University of Nebraska - Lincoln

DigitalCommons@University of Nebraska - Lincoln

Automated determination of precursor ion, product ion, and neutral loss compositions and deconvolution of composite mass spectra using ion correlation based on exact masses and relative isotopic abundances

Andrew H. Grange

U.S. Environmental Protection Agency, grange.andrew@epa.gov

G. Wayne Sovocool

U.S. Environmental Protection Agency

Follow this and additional works at: https://digitalcommons.unl.edu/usepapapers

Grange, Andrew H. and Sovocool, G. Wayne, "Automated determination of precursor ion, product ion, and neutral loss compositions and deconvolution of composite mass spectra using ion correlation based on exact masses and relative isotopic abundances" (2008). U.S. Environmental Protection Agency Papers. 128.

https://digitalcommons.unl.edu/usepapapers/128

This Article is brought to you for free and open access by the U.S. Environmental Protection Agency at DigitalCommons@University of Nebraska - Lincoln. It has been accepted for inclusion in U.S. Environmental Protection Agency Papers by an authorized administrator of DigitalCommons@University of Nebraska - Lincoln. 


\title{
Automated determination of precursor ion, product ion, and neutral loss compositions and deconvolution of composite mass spectra using ion correlation based on exact masses and relative isotopic abundances ${ }^{\dagger}$
}

\author{
Andrew H. Grange ${ }^{\star}$ and G. Wayne Sovocool \\ U.S. EPA, National Exposure Research Laboratory, Environmental Sciences Division, PO Box 93478, Las Vegas, NV 89193-3478, USA \\ Received 24 March 2008; Revised 29 May 2008; Accepted 29 May 2008
}

\begin{abstract}
After an accidental, deliberate, or weather-related dispersion of chemicals (dispersive event), rapid determination of elemental compositions of ions in mass spectra is essential for tentatively identifying compounds. A direct analysis in real time (DART) ${ }^{\circledR}$ ion source interfaced to a JEOL AccuTOF ${ }^{\circledR}$ mass spectrometer provided exact masses accurate to within $2 \mathrm{mDa}$ for most ions in full scan mass spectra and relative isotopic abundances (RIAs) accurate to within 15-20\% for abundant isotopic ions. To speed determination of the correct composition for precursor ions and most product ions and neutral losses, a three-part software suite was developed. Starting with text files of $\mathrm{m} / \mathrm{z}$ ratios and their ion abundances from mass spectra acquired at low, moderate, and high collision energies, the ion extraction program (IEP) compiled lists for the most abundant monoisotopic ions of their exact masses and the RIAs of the +1 and +2 isotopic peaks when abundance thresholds were met; precursor ions; and higher-mass, precursor-related species. The ion correlation program (ICP) determined if a precursor ion composition could yield a product ion and corresponding neutral loss compositions for each product ion in turn. The input and output program (IOP) provided the ICP with each precursor ion:product ion pair for multiple sets of error limits and prepared correlation lists for single or multiple precursor ions. The software determined the correct precursor ion compositions for 21 individual standards and for three- and seven-component mixtures. Partial deconvolution of composite mass spectra was achieved based on exact masses and RIAs, rather than on chromatography. Published in 2008 by John Wiley \& Sons, Ltd.
\end{abstract}

Identifying contaminants is the first step in assessing human health and ecological risks posed by contaminated sites. Thorough and rapid mapping of chemicals dispersed by an accidental, deliberate, or weather-related, event requires fast analyses and a high throughput. To meet this need, an autosampler/direct analysis in real time $\left(\mathrm{DART}^{\mathbb{R}}\right.$ ) ion source/time-of-flight mass spectrometer $\left(\right.$ TOFMS) ${ }^{1}$ that could be transported to dispersive events within a van and a wipe sample transport and collection device ${ }^{2}$ are under development. Cotton swab, wipe samples could be collected by numerous field samplers and rapidly analyzed using this instrument.

Wipe samples collected near the origin of a dispersive event should pick up relatively large amounts of the dispersed chemicals. For polar compounds desorbed and ionized by a heated stream of metastable helium atoms, the predominant

*Correspondence to: A. H. Grange, U.S. EPA, National Exposure Research Laboratory, Environmental Sciences Division, PO Box 93478, Las Vegas, NV 89193-3478, USA.

E-mail: grange.andrew@epa.gov

${ }^{\dagger}$ This article is a U.S. Government work and is in the public domain in the U.S.A. ions observed in the mass spectra should be from the dispersed compounds. The exact mass and relative isotopic abundance (RIA) measurements from the TOFMS will enable determination of the compositions of the ions in the mass spectra and provide rapid tentative identifications for chemicals listed in an exact mass and RIA library. ${ }^{3}$ After making a tentative identification, the same mass spectra acquired under the same conditions (and retention times when chromatography is used) for the analyte and a standard are still required for confirmation. For non-target compounds and for mixtures of compounds that provide composite mass spectra, software for determining ion compositions and deconvoluting mass spectra are essential. Once characteristic ions for dispersed compounds have been found, semiquantitative dispersion maps can be plotted using their ion abundances. Superfund (abandoned toxic waste) sites could also be better characterized using this technology to identify 'hot spots' where different types of chemical wastes were dumped. For both dispersive and Superfund sites, the high throughput of the autosampler would provide rapid analyses of large numbers of wipe samples to map contamination, guide remediation, and document a thorough clean-up. 
Simple and automated data acquisition, data processing, and data interpretation are essential for rapid and reliable analyses by an on-site operator within the van who might have security clearance, but have little experience with sample extraction, extract clean-up, chromatography, or mass spectrometry. Conventional analyses entailing such pre-analysis sample preparation and component separation would require additional instrumentation and numerous supplies, and of the order of $50 \mathrm{~min} /$ sample. The analysis time for each cotton swab using the wipe sample carrier ${ }^{2}$ and autosampler ${ }^{1}$ developed in-house is expected to be about 10 $20 \mathrm{~s} / \mathrm{swab}$. We have developed a positive mode, full-scan data acquisition method for recording the data needed to determine ion compositions. This acquisition method is much simpler than the ion-specific, selected ion recording method used in past work to plot mass peak profiles to obtain exact masses and RIAs for one ion at a time. ${ }^{4-6}$ A mass peak profile is the distribution of ion abundances observed before the raw data is centroided.

With minimal user input, the data interpretation software rapidly and routinely provides elemental compositions that correspond to protonated molecules (the precursor ions), $[\mathrm{M}+\mathrm{H}]^{+}$; ammoniated molecules, $\left[\mathrm{M}+\mathrm{NH}_{4}\right]^{+}$; protonated dimer species, $[\mathrm{M}+\mathrm{H}+\mathrm{M}]^{+}$; oxygenated species, $[\mathrm{M}+\mathrm{O}+\mathrm{H}]^{+}$; and to product ions observed in mass spectra and the neutral losses from the precursor ion that produced the product ions. The output of the software provides only essential information, consisting of a list of exact masses and RIAs, the corresponding possible compositions for each exact mass, and a list of unique precursor ion-product ion correlations. Usually, only one composition remains viable for each precursor ion and often also for all product ions and neutral losses.

The trade-off for this major speed enhancement is that composite mass spectra will often be obtained from individual swabs. Lacking chromatographic separation, we have developed automated deconvolution based on exact masses and RIAs of the precursor ion and product ions and their corresponding neutral losses (product ion:neutral loss pairs).

\section{Past efforts}

Several groups have determined ion compositions from exact masses and RIAs. ${ }^{3-12}$ Ojanperä et al. ${ }^{3}$ compiled a library of 735 target compounds of toxicological interest including the exact mass and RIAs of the protonated molecule against which measured values for drugs and their metabolites found in autopsy urine samples were searched. Mass error limits of \pm 10 ppm and a SigmaFit ${ }^{\mathrm{TM}}$ of 0.3 were used. More compounds were correctly identified when the RIAs were considered than when they were not. Three other groups developed automated or partially automated approaches to determine precursor and product ion compositions for compounds not present in libraries. Suzuki et al. ${ }^{10}$ compiled lists of possible ion compositions within mass error limits of $\pm 2 \mathrm{ppm}$ and $\pm 5 \mathrm{ppm}$ for measured exact masses of precursor and product ions, respectively, using the composition generator of the data system. The +1 and +2 RIAs, considered accurate to within $\pm 20 \%$ as suggested by Ibáñez, ${ }^{7}$ were then used to limit the possible range of $\mathrm{C}$ atoms and the

Published in 2008 by John Wiley \& Sons, Ltd. numbers of $\mathrm{S}, \mathrm{Cl}$, and $\mathrm{Br}$ atoms in an ion, respectively. Kaufmann's fragmentation crawler (FCR $)^{12}$ also compiled lists of possible compositions for precursor and product ions using the composition generator of his data system with mass error limits of $\pm 4 \mathrm{ppm}$. Both the +1 and the +2 RIAs were then considered to eliminate compositions based on acceptable ranges for the numbers of $\mathrm{C}, \mathrm{S}, \mathrm{Cl}$, or $\mathrm{Br}$ atoms. The ion correlation program (ICP) of Grange and Sovocool ${ }^{8,11}$ permitted values and error limits to be specified for both exact mass and RIA measurements before compositions were generated by the program. For the ICP, written in QuickBASIC ${ }^{\circledR}$ version 4.5 (Microsoft Corp., Bellevue, WA, USA), memory limitations often compelled initial entry of both exact masses and RIAs for large-mass precursor ions $(>m / z 250)$ to eliminate calculated compositions inconsistent with the RIAs prior to storage of possible compositions in an array. Doing so reduced the number of possible compositions corresponding to each ion and neutral loss and, thereby, increased the upper mass limit for which the ICP could be used. It also avoided output of numerous incorrect compositions along with the correct ones. Providing only the relevant results provides simplicity, which is essential for the dispersive site application where speed is paramount.

The latter three groups ${ }^{8,10-12}$ used the compositions of their product ion:neutral loss pairs to reject incorrect compositions for the precursor ion. Suzuki et al. ${ }^{10}$ and Kaufmann ${ }^{12}$ used Visual Basic procedures. Kaufmann's FCR processed up to seven ions and considered up to 119 calculated compositions for each ion. When the ICP considered RIAs for one or more high-mass ions, up to eight ions were processed using QuickBASIC as up to 50 possible compositions were saved for each ion or neutral loss exact mass. Storage of 50 possible compositions that have passed both exact mass and RIA criteria corresponds to more than 119 compositions for which only exact masses have been considered. This memory conservation is illustrated by three random examples, the $[\mathrm{M}+\mathrm{H}]^{+}$precursor ions from caffeine, sulfamerazine, and chlorpromazine. When the elements $\mathrm{C}, \mathrm{H}, \mathrm{Cl}, \mathrm{N}, \mathrm{O}, \mathrm{P}$ and $\mathrm{S}$ were considered for calculated exact masses within a $\pm 2 \mathrm{mDa}$ window for the $m / z 195.08765,265.07537$ and 319.10302 ions, 14,51 and 86 possible compositions were listed. When RIAs within $20 \%$ of the calculated values were also considered, the numbers of possible compositions fell to 1, 5 and 4 , respectively.

\section{Error constraints}

All three groups noted that using wide error limits increased the number of possible compositions found, while narrow error limits could result in rejections of correct compositions. Fixed mass error limits were input into each program. Grange et al. ${ }^{11}$ started with generous mass error limits and then manually reduced them for multiple runs of the ICP until unique ion compositions were found. For this work, the use of multiple sets of mass and RIA error limits was automated to further reduce the experience and time required by the operator of an autosampler/DART/TOFMS at a dispersive event to determine the ion and neutral loss compositions helpful for identifying compounds. 


\section{EXPERIMENTAL}

\section{Autosampler/DART/TOFMS}

The autosampler consisted of a $1 / 4^{\prime \prime}$-square aluminum bar mounted on $\mathrm{N}$-scale model railroad flatcars that rode on $\mathrm{N}$-scale track. $\mathrm{N}$-scale is based on a spacing of $9 \mathrm{~mm}$ between the track rails, and a flatcar is a platform on wheels with no sides or roof. Cotton swabs mounted on the aluminum rod were pulled through the $300^{\circ} \mathrm{C}$, metastable $\mathrm{He}$ beam at $0.2 \mathrm{~cm} / \mathrm{s}$ by a 7-rpm DC motor. A full description of the autosampler can be found elsewhere. ${ }^{1}$

The direct analysis in real time $\left(\mathrm{DART}^{\mathbb{R}}\right)$ ion source (IonSense Inc., Saugus, MA, USA) provided ambient-air, surface sampling, where a heated, metastable He beam is directed toward the atmospheric sampling cone of an orthogonal-acceleration (oa) TOFMS. The DART source desorbed analytes on the surface of cotton swabs and ionized them through a process similar to atmospheric pressure chemical ionization (APCI). ${ }^{13}$

The DART source was interfaced to a JEOL AccuTOF ${ }^{\mathbb{R}}$ oaTOFMS (JEOL USA, Peabody, MA, USA). The fast analog-todigital converter detector provided a linear dynamic range of about $10^{4}$, which provided RIAs not distorted by signal saturation of the monoisotopic ion.

\section{Standards}

Fourteen standards, (1)-(3) and (5)-(15) (listed in Table 1), were previously purchased from Aldrich (Milwaukee, WI, USA). These standards and pseudoephedrine (4) purchased as an over-the-counter cold remedy were used to estimate mass and RIA errors. Later, mass spectra were obtained for dichlorvos (16) from Chem Service (West Chester, PA, USA), pharmaceuticals (17)-(20) purchased by prescription from a pharmacy, and Sudan Red 7B (21) from Aldrich.

Table 1. Compounds investigated using the enhanced ICP

\begin{tabular}{|c|c|c|}
\hline Compound & $\begin{array}{l}\text { Exact } \\
\text { mass }\end{array}$ & $\begin{array}{c}\text { Precursor ion } \\
\text { composition of } \\
{[\mathrm{M}+\mathrm{H}]^{+}}\end{array}$ \\
\hline 1. 2-aminopyridine & 95.0604 & $\mathrm{C}_{5} \mathrm{H}_{7} \mathrm{~N}_{2}{ }^{\mathrm{b}}$ \\
\hline 2. $2,2^{\prime}$-thiodiethanol & 105.0369 & $\mathrm{C}_{4} \mathrm{H}_{11} \mathrm{O}_{2} \mathrm{~S}-\mathrm{H}_{2} \mathrm{O}$ \\
\hline 3. 2-amino-4,6-dimethylpyrimidine & 124.0869 & $\mathrm{C}_{6} \mathrm{H}_{10} \mathrm{~N}_{3}{ }^{\mathrm{b}}$ \\
\hline 4. pseudoephredine & 166.1226 & $\mathrm{C}_{10} \mathrm{H}_{16} \mathrm{NO}$ \\
\hline 5. 2-aminobiphenyl & 170.0964 & $\mathrm{C}_{12} \mathrm{H}_{12} \mathrm{~N}$ \\
\hline 6. phenazine & 181.0760 & $\mathrm{C}_{12} \mathrm{H}_{9} \mathrm{~N}_{2}$ \\
\hline 7. 9-methycarbazole & 182.0964 & $\mathrm{C}_{13} \mathrm{H}_{12} \mathrm{~N}$ \\
\hline 8. 2-(methylthio)benzothiazole & 182.0093 & $\mathrm{C}_{8} \mathrm{H}_{8} \mathrm{NS}_{2}^{\mathrm{a}, \mathrm{b}}$ \\
\hline 9. DEET & 192.1383 & $\mathrm{C}_{12} \mathrm{H}_{18} \mathrm{NO}^{\mathrm{b}}$ \\
\hline 10. caffeine & 195.0876 & $\mathrm{C}_{8} \mathrm{H}_{11} \mathrm{~N}_{4} \mathrm{O}_{2}$ \\
\hline 11. N-butylbenzenesulfonamide & 214.0896 & $\mathrm{C}_{10} \mathrm{H}_{16} \mathrm{NO}_{2} \mathrm{~S}^{\mathrm{b}}$ \\
\hline 12. carbamazepine & 237.1022 & $\mathrm{C}_{15} \mathrm{H}_{13} \mathrm{~N}_{2} \mathrm{O}^{\mathrm{b}}$ \\
\hline 13. sulfamerazine & 265.0754 & $\mathrm{C}_{11} \mathrm{H}_{13} \mathrm{~N}_{4} \mathrm{O}_{2} \mathrm{~S}^{\mathrm{a}}$ \\
\hline 14. tris(2-chloroethyl)phosphate & 284.9612 & $\mathrm{C}_{6} \mathrm{H}_{13} \mathrm{Cl}_{3} \mathrm{O}_{4} \mathrm{P}$ \\
\hline 15. chlorpromazine & 319.1030 & $\mathrm{C}_{17} \mathrm{H}_{20} \mathrm{ClN}_{2} \mathrm{~S}^{\mathrm{a}, \mathrm{b}}$ \\
\hline 16. dichlorvos & 220.9532 & $\mathrm{C}_{4} \mathrm{H}_{8} \mathrm{Cl}_{2} \mathrm{O}_{4} \mathrm{P}$ \\
\hline 17. ramelteon & 260.1645 & $\mathrm{C}_{16} \mathrm{H}_{22} \mathrm{NO}_{2}$ \\
\hline 18. metoprolol & 268.1907 & $\mathrm{C}_{15} \mathrm{H}_{26} \mathrm{NO}_{3}$ \\
\hline 19. cephalexin & 304.1114 & $\mathrm{C}_{16} \mathrm{H}_{18} \mathrm{~N}_{3} \mathrm{O}_{4} \mathrm{~S}-\mathrm{CO}_{2}$ \\
\hline 20. flecainide & 415.1451 & $\mathrm{C}_{17} \mathrm{H}_{21} \mathrm{~F}_{6} \mathrm{~N}_{2} \mathrm{O}_{3}$ \\
\hline 21. Sudan Red 7B & 380.1870 & $\mathrm{C}_{24} \mathrm{H}_{22} \mathrm{~N}_{5}$ \\
\hline
\end{tabular}

${ }^{\mathrm{a}}[\mathrm{M}+\mathrm{H}]^{+}$ions from compounds in the three-component mixture.

${ }^{b}[\mathrm{M}+\mathrm{H}]^{+}$ions from compounds in the seven-component mixture.

\section{Data acquisition}

A single full scan data acquisition over a mass range of $m / z 50$ 1000 recorded mass spectra with with three different voltages applied to orifice 1 as six cotton swabs mounted 1 " apart on a $1 / 4^{\prime \prime}$-square aluminum bar were pulled through the ionizing beam as illustrated in Fig. 1. To provide in-source collisionally induced dissociation (CID), the orifice 1 voltage was switched from $70 \mathrm{~V}$ to $40 \mathrm{~V}$ after $0.4 \mathrm{~min}$ and to $15 \mathrm{~V}$ after $0.8 \mathrm{~min}$. Swabs had been dipped into methanol solutions and allowed to dry. One solution contained the analyte and three others contained different mixtures of standards for mass calibration. For the orifice 1 voltage of $15 \mathrm{~V}$, a mixture of 2-aminopyridine, $\mathrm{N}, \mathrm{N}$-diethyl-meta-toluamide (DEET), and $\mathrm{N}$-butylbenzenesulfonamide provided seven calibrant ions between $\mathrm{m} / \mathrm{z} 95$ and 427: 95.0604 [M+H] ${ }^{+}, 192.1383[\mathrm{M}+\mathrm{H}]^{+}, 214.0896[\mathrm{M}+\mathrm{H}]^{+}, 286.1914$ [2-aminopryridine+DEET $+\mathrm{H}]^{+}, 308.1427$ [2-aminopryridine+ $\mathrm{N}$-butylbenzenesulfonamide $+\mathrm{H}]^{+}, \quad 383.2693 \quad[\mathrm{DEET}+\mathrm{H}+$ $\mathrm{DEET}^{+}$, and 427.1720 [N-butylbenzenesulfonamide $\left._{2}+\mathrm{H}\right]^{+}$. For the orifice 1 voltage of $70 \mathrm{~V}$, a mixture of 2-aminopyridine, 2-(methylthio)benzothiazole, DEET, caffeine, carbamazepine, and chlorpromazine provided up to 11 calibrant ions between $\mathrm{m} / \mathrm{z} 78$ and 335: $78.0338\left(\mathrm{C}_{5} \mathrm{H}_{4} \mathrm{~N}^{+}\right), 86.0964$ $\left(\mathrm{C}_{5} \mathrm{H}_{12} \mathrm{~N}^{+}\right), 95.0604[\mathrm{M}+\mathrm{H}]^{+}, 138.0662\left(\mathrm{C}_{6} \mathrm{H}_{8} \mathrm{~N}_{3} \mathrm{O}^{+}\right), 166.9858$ $\left(\mathrm{C}_{7} \mathrm{H}_{5} \mathrm{NS}_{2}^{+}\right), 182.0093[\mathrm{M}+\mathrm{H}]^{+}, 194.0964\left(\mathrm{C}_{14} \mathrm{H}_{12} \mathrm{~N}^{+}\right), 237.1022$ $[\mathrm{M}+\mathrm{H}]^{+}, 246.0139\left(\mathrm{C}_{13} \mathrm{H}_{9} \mathrm{ClNS}^{+}\right), 319.1030[\mathrm{M}+\mathrm{H}]^{+}$, and $335.0979\left(\mathrm{C}_{17} \mathrm{H}_{20} \mathrm{ClN}_{2} \mathrm{OS}^{+}\right)$. To create a calibrant for the orifice 1 voltage of $40 \mathrm{~V}$, these two mixtures were mixed, more $N$ butylbenzenesulfonamide was added to boost the $\mathrm{m} / \mathrm{z} 214$ ion, and 2-amino-4,6-dimethylpyrimidine was added to provide a $\mathrm{m} / \mathrm{z} 124$ ion. Up to nine ions were used in the calibration: $95.0604[\mathrm{M}+\mathrm{H}]^{+}, 124.0869[\mathrm{M}+\mathrm{H}]^{+}, 158.0270$ $\left(\mathrm{C}_{6} \mathrm{H}_{8} \mathrm{NO}_{2} \mathrm{~S}^{+}\right), 182.0093[\mathrm{M}+\mathrm{H}]^{+}, 192.1383[\mathrm{M}+\mathrm{H}]^{+}, 214.0896$ $[\mathrm{M}+\mathrm{H}]^{+}, 237.1022[\mathrm{M}+\mathrm{H}]^{+}, 319.1030[\mathrm{M}+\mathrm{H}]^{+}$, and 335.0979 $\left(\mathrm{C}_{17} \mathrm{H}_{20} \mathrm{ClN}_{2} \mathrm{OS}^{+}\right)$. These solutions were prepared to provide calibration across the mass ranges of interest at the three orifice 1 voltages. The concentrations of the solutions were not of interest in this qualitative study and were not estimated. An analyte swab preceded the appropriate calibrant swab for each orifice 1 voltage, as illustrated in Fig. 1.

\section{Instrument parameters}

Instrument parameters were set based on values recommended by the manufacturer, found by tuning the instrument for high resolution and high ion abundance, and by limited observation of the effect of limited ranges of variables on ion abundances. Only the positive ion mode was investigated. The instrument settings were: ring lens, $5 \mathrm{~V}$; orifice $1,15,40$, or $70 \mathrm{~V}$; orifice $2,5 \mathrm{~V}$; cone temperature, $120^{\circ} \mathrm{C}$; bias, $28 \mathrm{~V}$; pusher bias, $-0.50 \mathrm{~V}$; focus voltage, $-120 \mathrm{~V}$; focus lens, $-5 \mathrm{~V}$; quadrupole lens, $6 \mathrm{~V}$; right/left, $-15 \mathrm{~V}$; top/ bottom, $-2 \mathrm{~V}$; reflectron, $800 \mathrm{~V}$; pusher voltage, $778 \mathrm{~V}$; pulling voltage, $-778 \mathrm{~V}$; suppress voltage, $0.20 \mathrm{~V}$; flight tube, $-7.0 \mathrm{kV}$; detector, $2.4 \mathrm{kV}$, He temperature, $300^{\circ} \mathrm{C}$; spectrum accumulation time, $0.97 \mathrm{~s}$; and $\mathrm{He}$ flow, $3.15 \mathrm{~L} / \mathrm{min}$ (to provide a hiss). For the first 15 standards studied, the peak voltage was $1.0 \mathrm{kV}$. Later, the peak voltage was $600 \mathrm{~V}$ for orifice 1 voltages of 70 and $40 \mathrm{~V}$, to better ensure observation of lower-mass ions.

Rapid Commun. Mass Spectrom. 2008; 22: 2375-2390 


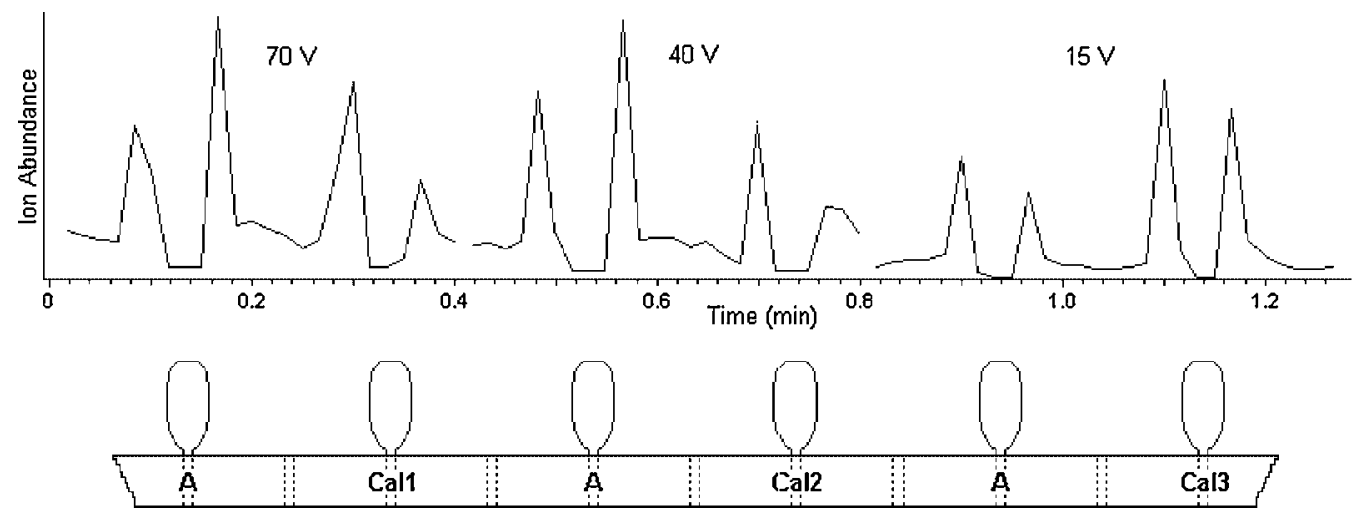

Figure 1. The total ion chromatogram obtained with orifice 1 voltages of 70,40 , and $15 \mathrm{~V}$ as cotton swabs previously dipped into a methanol solution of 2-amino-4,6-dimethylpyrimidine were pulled through the ionizing beam. Ion abundances were greatest when the ionizing beam grazed the leading and trailing edges of the swabs.

\section{RESULTS AND DISCUSSION}

\section{Three orifice 1 voltages}

For the high analyte levels expected on cotton swabs, wipe samples collected near the origin of a dispersive event, mass spectra obtained using the DART ion source can contain dimeric species including protonated dimers, ammoniated dimers, subunits of these species, and protonated bimolecular A:B adducts in addition to product ions from two or more different compounds. Although protonated and ammoniated dimer species from a single compound are easily identified as such, ions are often observed where a simple and immediate interpretation is questionable or not obvious. However, dimeric species usually fragmented at lower orifice 1 voltages than monomeric species. This observation was used to classify ions heavier in mass than the highest-mass protonated or ammoniated analyte molecule as being derived from dimeric species. Dimeric species were revealed not to be from additional analytes and they were not needed to determine the ion compositions of the analyte(s) responsible for them. Hence, data was recorded for each analyte using an orifice 1 voltage of $15 \mathrm{~V}$ to provide minimal fragmentation and ensure that precursor ions would be present, $40 \mathrm{~V}$ to completely fragment dimeric species, and $70 \mathrm{~V}$ to produce multiple product ions from the precursor ions. The orifice 1 voltages chosen were based on examination of mass spectra obtained for 15 simulated unknowns. Later, the orifice 1 voltage was increased from 70 to $90 \mathrm{~V}$ for one compound, flecainide, to provide greater fragmentation.

\section{Data system manipulations}

The mass spectra were acquired for an analyte with orifice 1 voltages of 70,40 , and $15 \mathrm{~V}$ using the data acquisition method described above. The user then manually displayed the total ion chromatogram, displayed mass spectra from the maximum of a chromatographic peak for the calibrant solution, centroided the mass peaks, and saved a calibration file. A mass spectrum from the maximum of a chromatographic peak of the analyte acquired at the same orifice 1 voltage was displayed, the mass peaks were centroided, and the exact masses of the ions were obtained by calibrating the analyte spectrum with the previously saved calibration file. The exact masses and ion abundances were then saved in a text file. This process was repeated for the other two orifice 1 voltages, and all three text files were imported into a folder on an ancillary personal computer. Because the data system lacked a macro language, these steps were performed manually.

\section{Three linked programs}

The ion correlation program (ICP) is now supplemented by an ion extraction program (IEP) and an input and output program (IOP), as shown in Fig. 2. The IEP automatically compiled lists of precursor, product, adduct, and other related ions from the text files prepared by the mass spectrometer data system and then invoked the IOP. The IOP sent the precursor ion mass and RIAs to the ICP, which determined the possible compositions for the precursor ion. The IOP then provided the ICP with the precursor ion and most abundant product ion exact masses, and for prominent product ions, RIAs from the lists prepared by the IEP. The ICP calculated possible compositions for the precursor, product ion, and its corresponding neutral loss. After each precursor ion:product ion cycle, the IOP updated a list of exact masses and possible compositions if the precursor and product ions were correlated and tightened the upper elemental composition limits when fewer precursor ion compositions were found. The cycles continued until all product ions listed by the IEP were considered by the ICP. This set of cycles was repeated for multiple sets of error limits. The IOP compiled a final list containing the precursor ion and product ion:neutral loss pair compositions found by the ICP and created an output file. The sets of cycles through the second and third programs were made for one or more precursor ions and their product ions gleaned from each set of mass spectra. The ICP displayed the compositions found for each precursor ion and product ion:neutral loss pair, which was essential for finding when errors occurred during program debugging. This display option slowed program execution, but revealed when a correct composition was eliminated. Such instances led empirically to exact mass tests 
Ion Extraction Program Input and Output Program lon Correlation Program

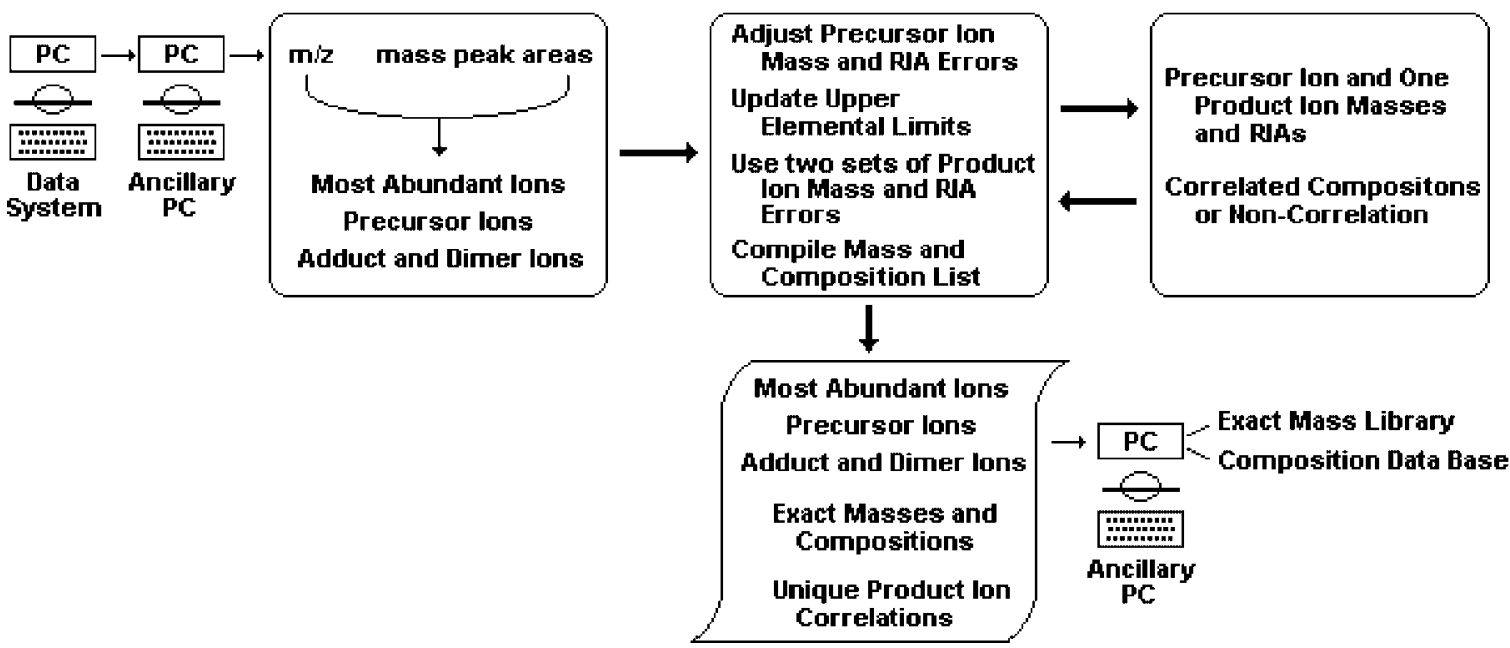

Figure 2. A diagram of the three programs listing their functions and interactions. A text file of $m / z$ values and mass peak areas from the data system yields an output that includes exact masses and corresponding compositions. Comparison of measured exact masses to calculated exact masses of precursor ions in a library or comparison of molecular compositions with those in a database such as SciFinder ${ }^{\circledR}$ often provide tentative identifications.

and sets of error limits that generally yielded a single, correct composition for precursor ions for which one or both RIAs were available.

\section{Ion extraction program}

While an experienced mass spectrometrist using a hand-held calculator to determine nominal mass differences can quickly suggest small neutral losses from a precursor ion to yield product ions, estimate the number of atoms of certain elements in ions from isotopic abundances, and ascertain which ions are adduct or dimeric species, personnel using the autosampler/DART/TOFMS in a van at a dispersive site probably could not. If multiple analytes produce the mass spectrum, even an expert could become confused. Instead, automated procedures should take full advantage of the exact masses for all ions and the RIAs for prominent ions obtained from the mass spectrum to interrelate the ions. Three text files were prepared from the three files imported from the data system that contained the exact masses and ion abundances acquired at the three orifice 1 voltages. Examples are shown in Table 2 for the $N$-butylbenzenesulfonamide mass spectra in Fig. 3(a) and the three-component mixture mass spectra shown in Fig. 3(b). The precursor ions are listed first in order of decreasing mass followed by the product ions in order of decreasing abundance.

\section{Ion abundance threshold tests}

Starting with the lowest mass ion from the $15 \mathrm{~V}$ spectrum, each precursor ion candidate was screened by a series of tests based on a minimum ion abundance threshold and exact mass differences. Precursor ions were usually prominent and were required to have a threshold exceeding 5000 counts and $2 \%$ of the ion abundance of the base peak in both the 15 and $40 \mathrm{~V}$ mass spectra. Dimeric species and their product ions were observed to fragment at $40 \mathrm{~V}$, while true precursor ions remained prominent in the mass spectrum.
When a lower-mass precursor ion was a compositional subunit of a higher-mass precursor ion, it was still recognized as a precursor ion due to its presence in both the 15 and $40 \mathrm{~V}$ mass spectra. Lower-mass precursor ions were not tested as product ion candidates from higher-mass precursor ions.

To be retained as a product ion from the $70 \mathrm{~V}$ mass spectrum, the ion abundance had to exceed a threshold adjusted to limit the number of product ions considered to a reasonable number. An initial threshold of 500 counts was used. If the number of product peaks exceeded 25 when only one precursor ion was found or 50 when more than one was found, the threshold was increased in increments of 500 counts until the number of product peaks was 25 (or 50) or less. Higher thresholds reduced the number of very low abundance ions correlated, which simplified the output. The compositions corresponding to prominent product ions from an analyte result from more facile fragmentations and can be used to deduce structural features of the molecule with greater confidence than compositions corresponding to ions with ion abundances near the threshold.

When +1 and +2 isotopic mass peaks were found by the exact mass tests described later, RIAs were calculated when certain signal thresholds were met in the $15 \mathrm{~V}$ mass spectrum. The $15 \mathrm{~V}$ spectrum provided the fewest product ions from higher-mass analytes to interfere with RIA measurements for lower-mass analytes. The \%1 RIA (+1 ion abundance/monoisotopic ion abundance $\times 100 \%$ ) or $\% 2$ RIA ( +2 ion abundance/monoisotopic ion abundance $\times$ $100 \%$ ) was calculated if the monoisotopic ion abundance exceeded 10000 counts and the +1 or +2 isotopic ion abundance exceeded 500 counts. A correction factor of 1.0466 was applied based on bias observed for 18 RIA measurements. If the monoisotopic ion abundance exceeded 100000 counts, 900 was added to the $\% 1$ RIA or $\% 2$ RIA to serve as a flag that the upper threshold was exceeded, in which case a lower RIA error limit was used when determining possible ion compositions. 
Table 2. Text files prepared by the ion extraction program

$\mathrm{N}$-butylbenzenesulfonamide

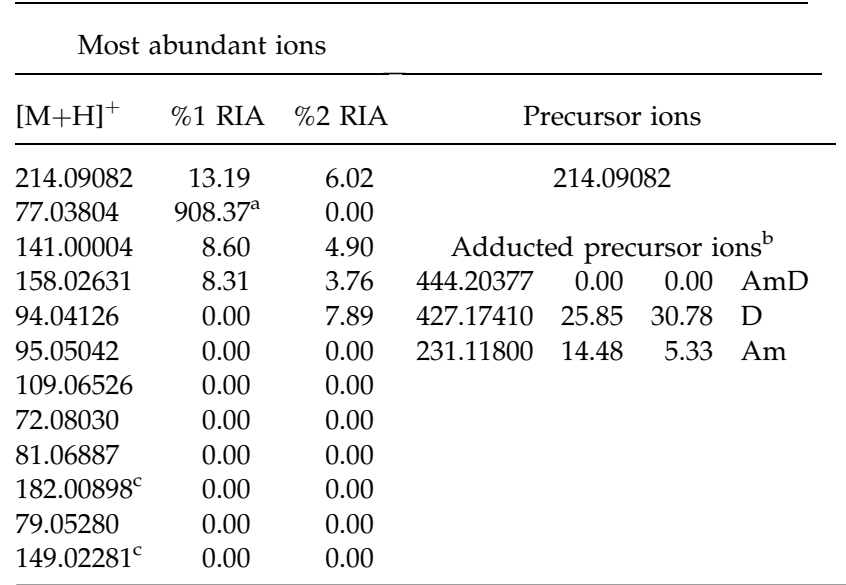

Mixture: chlorpromazine, sulfamerazine, and 2-(methylthio)benzothiazole.

\section{Most abundant ions}

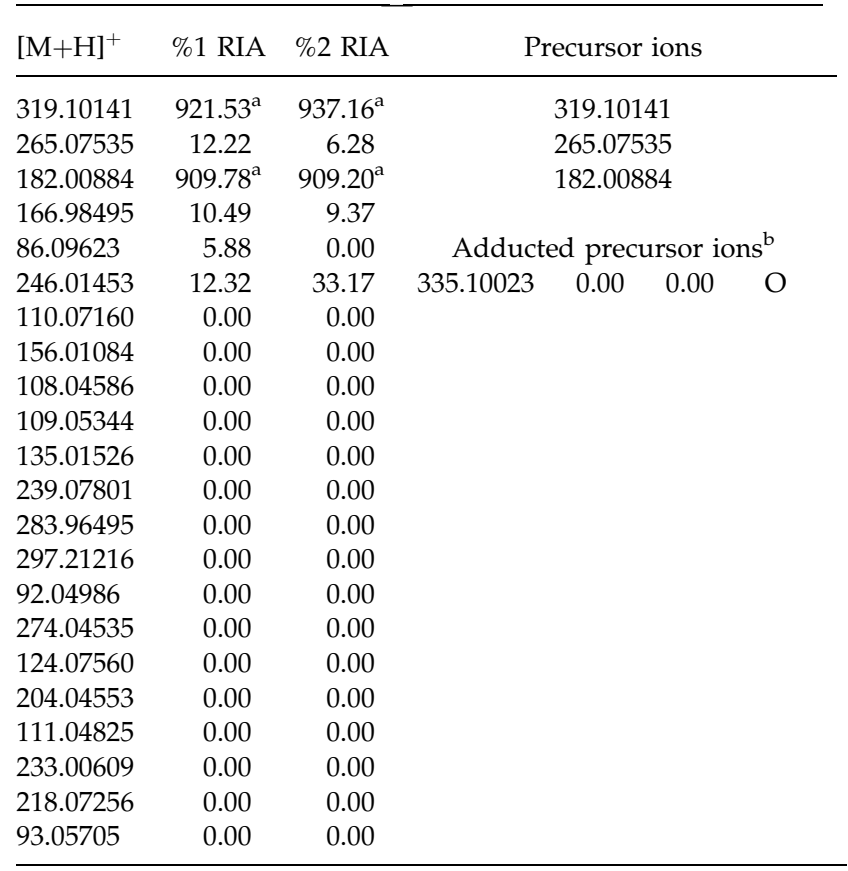

a As a program flag, 900 is added to calculated RIAs when the monoisotopic ion abundance exceeds 100,000 counts.

${ }^{\mathrm{b}}$ Label definitions: AmD (ammoniated dimer species), D (protonated dimer species), Am (ammoniated molecule), and O (oxygenated species).

${ }^{c}$ Did not correlate with the precursor ion. $m / z 182$ was $\mathrm{C}_{8} \mathrm{H}_{8} \mathrm{NS}_{2}^{+}$from a calibrant and $m / z 149$ was $\mathrm{C}_{8} \mathrm{H}_{5} \mathrm{O}_{3}^{+}$from one or more phthalate contaminants.

A \%1 RIA was calculated for the precursor ion or largest product ion for 20 of 21 compounds, and \%2 RIAs were obtained for 14 of the compounds. Either a low $\% 2$ RIA or the lack of a calculated $\% 2$ RIA indicated that no $\mathrm{S}, \mathrm{Cl}$, or $\mathrm{Br}$ atoms were present.

\section{Exact mass tests}

Only monoisotopic ions were listed in the IEP output.

1. For each possible precursor ion; higher-mass, precursorrelated species; or product ion, an ion smaller in mass by
0.992 to $1.0084 \mathrm{Da}$ or 1.9908 to $2.0117 \mathrm{Da}$ could not be present in the mass spectrum. If the exact mass fell within these ranges, the ion being considered was the +1 or +2 isotopic mass peak for the smaller-mass ion. The +1 isotopic mass defect differences for the elements considered are: ${ }^{13} \mathrm{C}-\mathrm{C}(0.0034 \mathrm{Da}),{ }^{14}{ }^{2} \mathrm{H}-\mathrm{H}(0.063 \mathrm{Da}),{ }^{15} \mathrm{~N}-$ $\mathrm{N}(-0.0030 \mathrm{Da}),{ }^{17} \mathrm{O}-\mathrm{O}(0.0042 \mathrm{Da}),{ }^{33} \mathrm{~S}-\mathrm{S}(-0.0006 \mathrm{Da})$, and ${ }^{29} \mathrm{Si}-\mathrm{Si}(-0.0004 \mathrm{Da})$. The isotopic abundances of ${ }^{2} \mathrm{H}$ and ${ }^{17} \mathrm{O}$ are only 0.0115 and 0.038 , respectively. The most positive value for +1 isotopes that strongly influence the exact mass of the +1 profile is 0.0034 Da for ${ }^{13} \mathrm{C}-\mathrm{C}$ and the most negative value is $-0.0030 \mathrm{Da}$ for ${ }^{15} \mathrm{~N}-\mathrm{N}$. A single ${ }^{13} \mathrm{C}$ atom will usually be most responsible for the exact mass of the +1 isotopic mass peak, but a compound with many $\mathrm{N}$ atoms will tend to reduce it. To provide a generous range for identifying +1 mass peaks, mass measurement error limits of $\pm 5 \mathrm{mDa}$ were added to the range of mass defect difference to provide a total range of -0.0080 to $+0.0084 \mathrm{Da}$. The mass difference range between the exact mass of the +1 isotopic mass peak and the monoisotopic mass peak is the mass defect difference range added to $1 \mathrm{Da}, 0.992$ to $1.0084 \mathrm{Da}$. Considering the +2 mass defect differences for ${ }^{81} \mathrm{Br}-\mathrm{Br} \quad(-0.0020 \mathrm{Da}),{ }^{37} \mathrm{Cl}-\mathrm{Cl}$ $(-0.0030 \mathrm{Da}),{ }^{18} \mathrm{O}-\mathrm{O} \quad(0.0042 \mathrm{Da}),{ }^{34} \mathrm{~S}-\mathrm{S} \quad(-0.0042 \mathrm{Da})$, ${ }^{30} \mathrm{Si}-\mathrm{Si}(-0.0032 \mathrm{Da})$, and $2\left({ }^{13} \mathrm{C}-\mathrm{C}\right)(0.0067 \mathrm{Da})$, the smallest and largest values are $-0.0042 \mathrm{Da}$ for ${ }^{34} \mathrm{~S}-\mathrm{S}$ and $+0.0067 \mathrm{Da}$ for $2\left({ }^{13} \mathrm{C}-\mathrm{C}\right)$. Allowing mass measurement error limits of $\pm 5 \mathrm{mDa}$, this range expands to -0.0092 to $+0.0117 \mathrm{Da}$. The mass difference range for the +2 isotopic mass peak is this range added to $2 \mathrm{Da}$, 1.9908 to $2.0117 \mathrm{Da}$.

In addition, to be a +1 profile, the +1 RIA could not exceed the value calculated as the +1 RIA contribution from the maximum number of ${ }^{29} \mathrm{Si}$ atoms possibly present, the maximum number of ${ }^{13} \mathrm{C}$ atoms possible for the mass remaining after subtracting the mass of the ${ }^{29} \mathrm{Si}$ atoms from the mass of the +1 profile candidate, and the maximum number of ${ }^{2} \mathrm{H}$ atoms for the mass remaining after subtracting the mass for the ${ }^{29} \mathrm{Si}$ and ${ }^{13} \mathrm{C}$ atoms.

2. For precursor and product ions, the monoisotopic ion was checked to ensure it was not a $+2,+4,+6$ or +8 isotopic ion of a previously found precursor or product ion that contained from one to four ${ }^{37} \mathrm{Cl}$ and $/$ or ${ }^{81} \mathrm{Br}$ atoms. The lower mass range limits for the mass difference between the monoisotopic and isotopic mass peaks for ions containing $1,2,3$ or $4,{ }^{37} \mathrm{Cl}$ or ${ }^{81} \mathrm{Br}$ atoms was the mass difference between the number of ${ }^{37} \mathrm{Cl}$ and $\mathrm{Cl}$ atoms minus $5 \mathrm{mDa}(1.99205,3.98910,5.98615$, and $7.98320 \mathrm{Da})$, while the upper mass range limits were the mass differences between the number of ${ }^{81} \mathrm{Br}$ and $\mathrm{Br}$ atoms plus $5 \mathrm{mDa}(2.00295,4.00091,5.99886$, and $7.99681 \mathrm{Da})$. In addition, for the +2 mass peak, the mass of the ion had to exceed the mass of a ${ }^{37} \mathrm{Cl}$ atom $(36.96590 \mathrm{Da})$ and the mass defect of the ion could not exceed the maximum allowed with a ${ }^{37} \mathrm{Cl}$ atom present. This maximum allowed mass defect was calculated by assuming the presence of a heteroatom $(\mathrm{N})$ to provide an $[\mathrm{M}+\mathrm{H}]^{+}$ion, one ${ }^{37} \mathrm{Cl}$ atom, and the remainder of the mass was accounted for by $\mathrm{CH}_{2}$ groups, which provide a large positive mass defect 

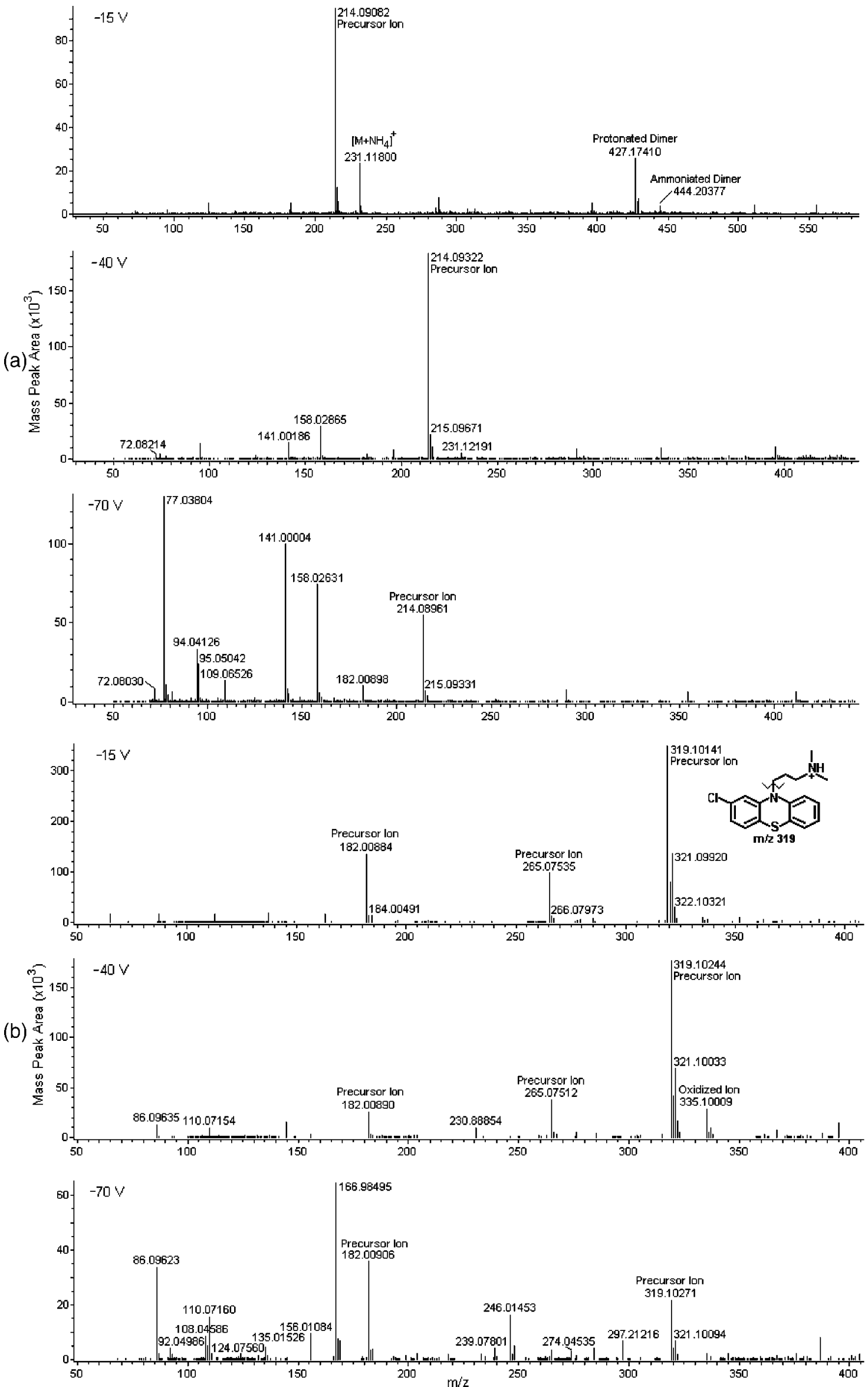

Figure 3. Mass spectra acquired with minimal, moderate, and major fragmentation for (a) $\mathrm{N}$-butylbenzenesulfonamide and (b) a mixture of 2-(methylthio)benzothiazole, sulfamerazine, and chlorpromazine. 
contribution. The number of $\mathrm{CH}_{2}$ groups was taken as the integer of the mass of the ion less the masses of $\mathrm{a}^{37} \mathrm{Cl}$ atom and $\mathrm{N}$ atom divided by $14.01565 \mathrm{Da}$, the mass of a $\mathrm{CH}_{2}$ group. The maximum mass defect was then the mass defect contributions from a ${ }^{37} \mathrm{Cl}$ atom, an $\mathrm{N}$ atom, and the number of $\mathrm{CH}_{2}$ groups times the mass defect for a $\mathrm{CH}_{2}$ group. The mass defects for the +2 isotopic peaks of protonated chloroaniline and protonated octylamine are 0.02326 and 0.16541 , respectively. The corresponding maximum estimated allowed mass defects for inclusion of a ${ }^{37} \mathrm{Cl}$ atom are both 0.04722 . Hence, by this test chloroaniline could contain a ${ }^{37} \mathrm{Cl}$ atom, while octylamine could not. This last test is an example of 'debugging'. An instance was found where a monoisotopic ion passed the mass difference range of $\mathrm{a}+2$ isotopic mass peak. This last test corrected this error.

\section{Additional precursor ion exact mass tests}

Several exact mass tests were applied only to precursor ions.

1. Candidate precursor ions from the $15 \mathrm{~V}$ mass spectrum with masses that were within $5 \mathrm{mDa}$ of higher-mass ions minus the mass of one or two $\mathrm{H}$ atoms were product ions rather than precursor ions.

2. If the mass of the candidate ion was $150.11247 \pm 5 \mathrm{mDa}$, it was assumed to be the $\mathrm{C}_{6} \mathrm{H}_{16} \mathrm{NO}_{3}^{+}$ion formed from triethanolamine, a common skin cream ingredient. Other such filters could be added quickly for commonly observed contaminants frequently observed at a particular location. Once the origin of the ion was determined, more careful handling of the swabs eliminated its presence in the mass spectra.

3. If an ion having at least $0.5 \%$ of the candidate ion's abundance had a mass larger by $18.010565 \pm 5 \mathrm{mDa}$, then the candidate ion was a $\left[\mathrm{M}+\mathrm{H}-\mathrm{H}_{2} \mathrm{O}\right]^{+}$ion and the highermass ion was saved as the precursor ion.

4. A check was made to ensure the candidate ion was not previously determined to be an ammonium adduct ion, protonated dimer species, ammoniated dimer species, oxygenated species, protonated dimer minus a $\mathrm{H}_{2} \mathrm{O}$ species, +1 or +2 isotopic mass peak, or $+2,+4,+6$, or +8 isotopic mass peaks resulting from ${ }^{37} \mathrm{Cl}$ and $/$ or ${ }^{81} \mathrm{Br}$ atoms.

\section{Exact mass tests for higher-mass ions related to the precursor ion}

Several tests were made to search for higher-mass ions related to the precursor ion. When these higher-mass ions were considered later, they were rejected as precursor ions from additional analytes.

1. To find a species containing an additional $\mathrm{O}$ atom, the mass filter was the mass of the precursor ion plus the mass of an $\mathrm{O}$ atom, $15.994915 \mathrm{Da}, \pm 5 \mathrm{mDa}$. Such a species was observed for chlorpromazine.

2. The mass filter to find an ammoniated adduct ion was the mass of $\mathrm{NH}_{3}, 17.02600 \mathrm{Da}, \pm 5 \mathrm{mDa}$. Two standards, $\mathrm{N}$ butylbenzenesulfonamide and tris(2-chloroethyl)phosphate, provided ammoniated adduct ions. For a cotton swab dipped into a solution of the first standard, inserting the swab into the operator's open mouth and exhaling across the swab elevated the proportion of ammoniated adduct present. No other source of ammonia was evident in the room. Hence, the operator seems to provide sufficient ammonia for these adducts to form. ${ }^{15}$

3. The mass filter for a protonated dimer that had lost a water molecule was twice the measured exact mass of the precursor ion less the masses of $\mathrm{H}_{2} \mathrm{O}(18.010565 \mathrm{Da})$ and a proton (1.007276 Da), $\pm 15 \mathrm{mDa}$. Such an ion was found for 2,2'-thiodiethanol

4. To find a protonated dimer, the mass filter was twice the mass of the precursor ion minus the mass of a proton, $1.007276 \mathrm{Da}, \pm 15 \mathrm{mDa}$. DEET, N-butylbenzenesulfonamide, carbamazepine, tris(2-chloroethyl)phosphate, ramelteon, metoprolol and flecainide provided prominent protonated dimer mass peaks.

5. The mass filter for an ammoniated dimer ion was twice the mass of the precursor ion less the mass of a proton (1.007276 Da) plus the mass of $\mathrm{NH}_{3},(17.02655 \mathrm{Da})$, $\pm 15 \mathrm{mDa}$. $N$-Butylbenzenesulfonamide provided a low abundance of its ammoniated dimer ion.

A methanol-adducted precursor ion was observed at $\mathrm{m} / \mathrm{z} 317$ in the mass spectrum acquired with an orifice 1 voltage of $15 \mathrm{~V}$ for tris(2-chloroethyl)phosphate. In mass spectra acquired with an orifice 1 voltage of $70 \mathrm{~V}$, methanoladducted product ions from precursor ions that had lost $\mathrm{NH}_{3}$ were observed at $m / z 110$ and 139 for 2-aminopyridine (Fig. 4(a)) and 2-amino-4,6-dimethylpyrimidine (Fig. 4(b)), respectively. Solvated product ions at $\mathrm{m} / \mathrm{z} 124$ and 204 were observed for sulfamerazine (Fig. 4(c)). Exact mass tests to find these types of ions based on the solvent in use could be easily added, but the simpler solution was to allow the swabs to dry, after which these ions disappeared. However, these results suggest that ambient air provides an environment where ion-molecule reactions can occur, especially at higher orifice 1 voltages that provide collisional energy.

\section{An additional test for product ions}

The text file from the data system acquired with an orifice 1 voltage of $70 \mathrm{~V}$ was opened and the ions were tested as described above starting with the lowest-mass ion. An additional test was applied to these ions. Checks were made to determine if the next highest mass ion was the current ion plus one or two $\mathrm{H}$ atoms ( 1 or $2 \times 1.007825 \mathrm{Da}$ $\pm 5 \mathrm{mDa}$ ). If so, no +1 or +2 isotopic mass peak tests were run.

\section{Output files from the IEP}

Table 2 provides output files for $N$-butylbenzenesulfonamide and a three-component mixture prepared after all precursor and product ions had undergone the tests described above. The +1 and +2 isotopic peak masses are not listed, but the RIAs are present when the signal thresholds were exceeded. Ions with higher masses than the highest-mass precursor ion were discarded as adduct or dimeric species, their product ions, or extraneous ions resulting from ion-molecule reactions and were not listed among the 'most abundant ions', which were later tested for correlations. To account for their presence, however, several high-mass ions visible in Fig. 3, an ammoniated dimer 
(a)
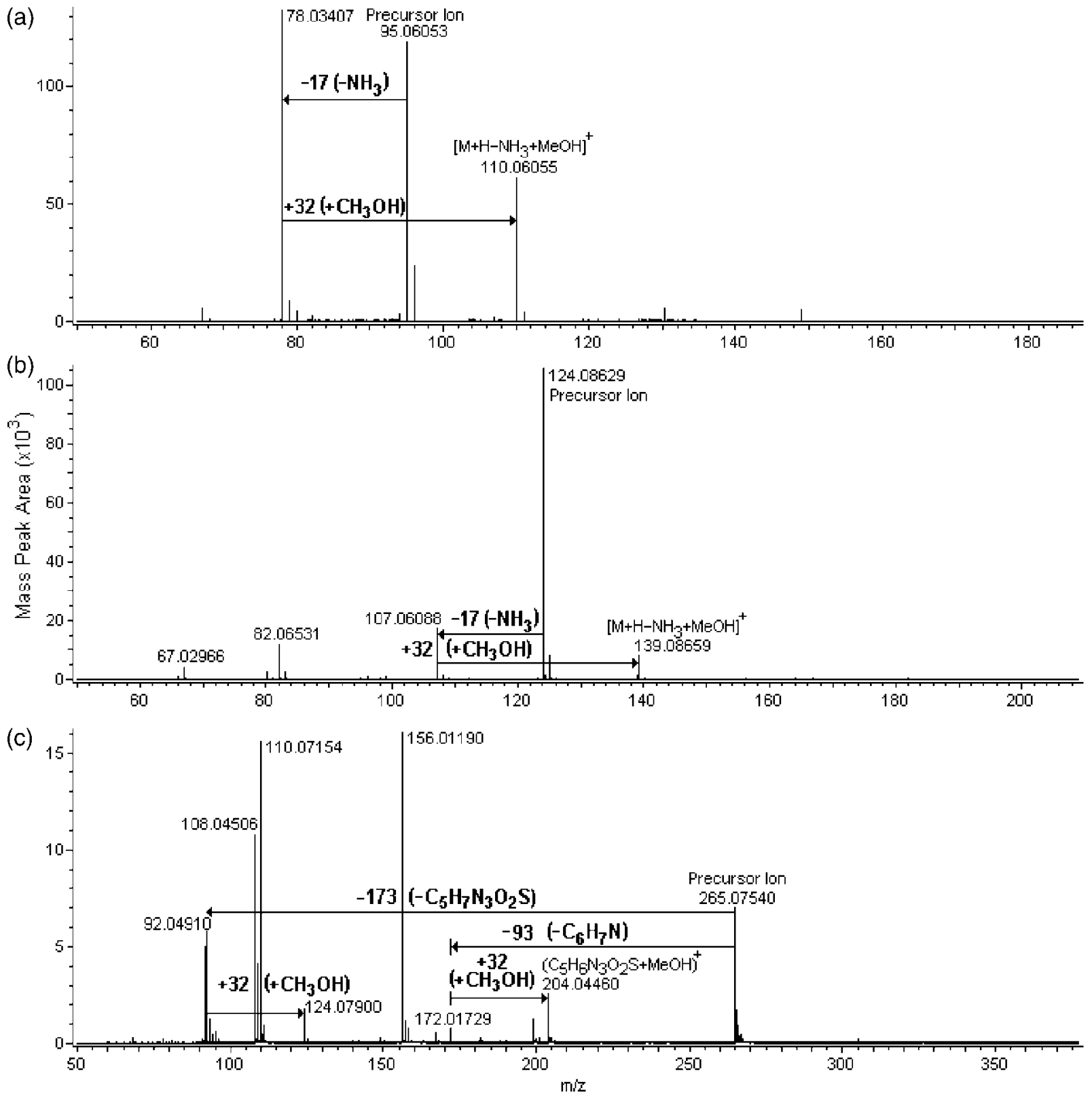

Figure 4. Uncentroided mass spectra acquired with an orifice 1 voltage of $70 \mathrm{~V}$ from wet cotton swabs dipped into methanol solutions of (a) 2-aminopyridine, (b) 2-amino-4,6-dimethylpyrimidine, and (c) sulfamerazine. The compounds yielded solvated product ions.

species, a protonated dimer species, and an ammoniated molecule from $\mathrm{N}$-butylbenzenesulfonamide and an oxygenated species from chlorpromazine, were listed as 'adducted precursor ions'.

\section{Ion correlation program (ICP)}

As fully described previously, ${ }^{8,11}$ the ICP compiled lists of possible compositions for the precursor ion and up to seven product ion:neutral loss pairs; determined which precursor ion, product ion, and neutral loss compositions were consistent with one another; and printed out only the compositions that were correlated.

Limiting ion correlation to seven product ion:neutral loss pairs is not a serious constraint when mass spectra for chromatographically well-separated analytes are investigated. Composite mass spectra often, however, contain dozens of product ions from multiple analytes for which Published in 2008 by John Wiley \& Sons, Ltd. correlations and non-correlations with each precursor ion are needed to achieve full or partial mass spectral deconvolution.

\section{Single precursor ion:product ion correlations}

A new strategy for using the ICP was developed to overcome the eight-ion memory limitation imposed by simultaneously considering multiple product ions. Instead, only the precursor ion and one product ion:neutral loss pair are now considered at a time. Correlation is tested first for the most abundant product ion and finally for the least abundant product ion to reduce the likelihood that correlation with a low-abundance product ion could eliminate the correct precursor ion composition before correlations with more abundant product ions have eliminated the incorrect precursor ion compositions. This approach permitted storage of up to 250 compositions for each ion and each neutral loss. 
Table 3. Possible ion compositions for the metoprolol precursor ion and three product ion:neutral loss pairs

\begin{tabular}{ll}
\hline Precursor ion & \\
268.18932 & $\mathrm{C}_{11} \mathrm{H}_{22} \mathrm{~N}_{7} \mathrm{O}^{+}, \mathrm{C}_{13} \mathrm{H}_{28} \mathrm{~F}_{2} \mathrm{NS}^{+}, \mathrm{C}_{13} \mathrm{H}_{25} \mathrm{~F}_{3} \mathrm{NO}^{+}$, \\
Correlations & $\mathrm{C}_{15} \mathrm{H}_{26} \mathrm{NO}_{3}^{+a}$ \\
268.18932 & $\mathrm{C}_{11} \mathrm{H}_{22} \mathrm{~N}_{7} \mathrm{O}^{+}, \mathrm{C}_{13} \mathrm{H}_{25} \mathrm{~F}_{3} \mathrm{NO}^{+}, \mathrm{C}_{15} \mathrm{H}_{26} \mathrm{NO}_{3}^{+}$ \\
116.10705 & $\left(\mathrm{C}_{4} \mathrm{H}_{12} \mathrm{~N}_{4}^{+}+\mathrm{C}_{7} \mathrm{H}_{10} \mathrm{~N}_{3} \mathrm{O}\right)$ or $\left(\mathrm{C}_{6} \mathrm{H}_{14} \mathrm{NO}^{+}+\mathrm{C}_{5} \mathrm{H}_{8} \mathrm{~N}_{6}\right.$, \\
& $\mathrm{C}_{7} \mathrm{H}_{11} \mathrm{~F}_{3}$, or $\left.\mathrm{C}_{9} \mathrm{H}_{12} \mathrm{O}_{2}\right)$ \\
268.18932 & $\mathrm{C}_{11} \mathrm{H}_{22} \mathrm{~N}_{7} \mathrm{O}^{+}, \mathrm{C}_{15} \mathrm{H}_{26} \mathrm{NO}_{3}^{+}$ \\
191.10639 & $\left(\mathrm{C}_{10} \mathrm{H}_{13} \mathrm{~N}_{3} \mathrm{O}^{+}+\mathrm{CH}_{9} \mathrm{~N}_{4}\right)$ or $\left(\mathrm{C}_{12} \mathrm{H}_{15} \mathrm{O}_{2}^{+}+\mathrm{C}_{3} \mathrm{H}_{11} \mathrm{NO}\right)$ \\
268.18932 & $\mathrm{C}_{15} \mathrm{H}_{26} \mathbf{N O}_{3}^{+}$ \\
226.14404 & $\mathrm{C}_{12} \mathrm{H}_{20} \mathrm{NO}_{3}^{+}+\mathrm{C}_{3} \mathrm{H}_{6}$ \\
Re-correlations & \\
268.18932 & $\mathrm{C}_{15} \mathrm{H}_{26} \mathrm{NO}_{3}^{+}$ \\
116.10705 & $\mathrm{C}_{6} \mathrm{H}_{14} \mathrm{NO}^{+}+\mathrm{C}_{9} \mathrm{H}_{12} \mathrm{O}_{2}$ \\
268.18932 & $\mathrm{C}_{15} \mathrm{H}_{26} \mathbf{N O}_{3}^{+}$ \\
191.10639 & $\mathrm{C}_{12} \mathrm{H}_{15} \mathrm{O}_{2}^{+}+\mathrm{C}_{3} \mathrm{H}_{11} \mathrm{NO}$ \\
\hline
\end{tabular}

${ }^{\mathrm{a}}$ The correct precursor ion composition is in bold type.

The possible compositions for the precursor ion were used to establish new upper elemental limits for the precursor ion after each correlation with a product ion:neutral loss pair. In this way, the restrictions placed on the precursor ion compositions by each product ion:neutral loss pair were retained before attempting to correlate the next most abundant ion with the precursor ion. This approach was not as restrictive on the numbers of precursor and product ion compositions as considering seven correlated product ions at once, since the restrictions imposed by all product ion:neutral loss pairs were only applied to the last correlated product ion:neutral loss pair.

The compositions listed in Table 3 for the $m / z 268$ precursor ion from metoprolol and three product ions illustrate this point. Four precursor ion compositions were possible before the most abundant product ion was tested for correlation. Correlation with the $\mathrm{m} / \mathrm{z} 116$ product ion:neutral loss pair eliminated one precursor ion composition, while two $\mathrm{m} / \mathrm{z} 116$ product ion compositions remained possible. After correlation with the $m / z 191$ product ion:neutral loss pair, two compositions were possible for the precursor ion and two compositions for the $\mathrm{m} / \mathrm{z} 191$ product ion. The six most abundant product ions not yet tested all correlated with the two remaining precursor ion compositions. Finally, correlation with the $m / z 226$ ion eliminated the incorrect precursor composition so that only the correct one remained.

\section{Re-correlation}

Using the single precursor ion composition to provide the upper elemental limits, re-correlation with the $m / z 116,191$, and 14 other product ion:neutral loss pairs provided a single composition for each of the 16 product ions. To ensure that each product ion:neutral loss pair is tested against the tightest upper elemental composition limits found after all correlations have been made, the ICP re-correlates all product ions after all product ion:neutral loss pairs have been tested, if the upper elemental limits changed after the first product ion:neutral loss correlation. When more restrictive upper error limits were used, a previous correlation could fail and remove a spurious product ion:neutral loss pair previously correlated. In addition, one or more spurious possible compositions for product ion:neutral loss pairs could fail leaving fewer possible compositions for exact masses that still correlated.

Re-correlating all product ion:neutral loss pairs with the precursor ion using the most restrictive error limits found for the precursor ion provides the same number of compositions for all ions and neutral losses as does considering all of the product ion:neutral loss pairs simultaneously. The advantage of this new approach is that there is no limitation on the number of product ions that can be considered. Simultaneously testing the product ions listed in Table 1 from the mass spectra in Fig. 3(b) for the mixture of 2(methylthio)benzothiazole, sulfamerazine, and chlorpromazine provided lists of seven correlated product ion:neutral loss pairs for two of the compounds. The ion lists in Table 4 compiled using individual product ion correlation followed by re-correlation contain 12 product ion:neutral loss correlations for both the $\mathrm{m} / \mathrm{z} 319$ and the $\mathrm{m} / \mathrm{z} 265$ precursor ions. The ability to test correlation for a large number of product ions is essential when mixtures of analytes provide many product ions. Although only partial deconvolution of the mass spectra was achieved, the single, correct composition was determined for all three protonated molecules when $\mathrm{C}, \mathrm{H}, \mathrm{N}, \mathrm{O}, \mathrm{S}$ and $\mathrm{P}$ (and $\mathrm{Cl}$ for the $\mathrm{m} / \mathrm{z} 319$ precursor ion) were the elements considered.

The ICP received the exact masses and RIAs, if calculated, for the precursor ion and one product ion from the IOP. The corresponding neutral loss mass was calculated as the mass difference. The precursor ion, but not the product ions, was assumed to be an even-electron ion.

\section{Elemental limits}

Lower elemental limits for the precursor ion previously provided by the user are now determined automatically based on two assumptions.

1. A single $\mathrm{Cl}$ atom provides $32 \%$ to the $\% 2$ RIA. When the $\% 2$ RIA fell within the range $25 \%$ to $55 \%$ or $925 \%$ to $955 \%$, depending on the signal threshold for the monoisotopic ion, one $\mathrm{Cl}$ atom was assumed to be present in the precursor ion. If the $\% 2$ RIA fell between 55\% and $80 \%$ or between $955 \%$ and $980 \%$, two $\mathrm{Cl}$ atoms were assumed to be present.

2. If the $\% 2$ RIA was between $4 \%$ and $25 \%$ (or between $904 \%$ and $925 \%$ ), the maximum contribution to the $\% 2$ RIA from carbon was estimated by assuming that $85 \%$ of the mass of the ion was due to carbon. The $\% 2$ RIA contribution from the corresponding integer number of $\mathrm{C}$ atoms was subtracted from the total $\% 2$ RIA and the integer of the remaining $\% 2$ RIA divided by $4.43 \%$ was used as the lower limit for the number of $\mathrm{S}$ atoms. This approach can be in error by providing too few $\mathrm{S}$ atoms, which is acceptable, whereas an overestimation of the number of $S$ atoms could result in the correct composition of the precursor ion being excluded by the lower elemental limits.

Higher elemental limits were also estimated automatically.

1. The maximum numbers of atoms of $\mathrm{C}, \mathrm{H}, \mathrm{N}, \mathrm{O}$ and $\mathrm{S}$ were determined as the integer of the precursor ion's mass divided by the atomic mass of each element. If the user 
Table 4. Output from the input and output program for a three-component mixture

Exact Masses \& Poss. Comps.

Lower Elemental Limits: $\mathrm{Cl}$

Upper Limits: C26 H316 N22 O19 S9 P10 Cl2

Mass \& RIA Errors: $2 \mathrm{mDa} 20 \%$

319.10141 Precursor Ion

C17 H20 N2 S Cl (8.5) -1.6

(1) 86.09623 Product Ion

C5 H12 N (0.5) -0.2

(2) 246.01453 Product Ion

C13 H9 N S Cl (9.5) 0.7

(3) 108.04586 Product Ion

C3 H9 N2 Cl (0.0) 1.0

(4) 109.05344 Product Ion

C3 H10 N2 Cl (-0.5) 0.7

(5) 135.01526 Product Ion

C7 H5 N S (6.0) 1.5

(6) 239.07800 Product Ion

C15 H13 N S (10.0) 1.7

(7) 92.04986 Product Ion

C6 H6 N (4.5) 0.4

(8) 274.04535 Product Ion

C15 H13 N S Cl (9.5) 0.2

(9) 204.04553 Product Ion

C11 H9 N2 Cl (8.0) 0.7

(10) 233.00609 Product Ion

C12 H8 N S Cl (9.0) 0.0

(11) 218.07256 Product Ion

C13 H13 N Cl (7.5) -0.5

(12) 93.05705 Product Ion

C6 H7 N (4.0) -0.3

(12) 226.04436 Neutral Loss

C11 H13 N S Cl (5.5) -1.4

(11) 101.02885 Neutral Loss

C4 H7 N S (2.0) -1.1

(10) 86.09532 Neutral Loss

C5 H12 N (0.5) -0.7

(9) 115.05588 Neutral Loss

C6 H11 S (1.5) -2.3

(8) 45.05606 Neutral Loss

C2 H7 N (0.0) - 1.8

(7) 227.05154 Neutral Loss

C11 H14 N S Cl (5.0) -2.0

(6) 80.02340 Neutral Loss

C2 $\mathrm{H} 7 \mathrm{~N} \mathrm{Cl}(-0.5)-3.3$

(5) 184.08615 Neutral Loss

C10 H15 N CL (3.5) -3.2

(4) 210.04797 Neutral Loss

C14 H10 S (10.0) -2.4

(3) 211.05556 Neutral Loss

C14 H11 S (9.5) -2.6

(2) 73.08688 Neutral Loss

C4 H11 N (0.0) -2.3

(1) 233.00517 Neutral Loss

C12 H8 N S Cl (9.0) - 0.5
Exact Masses \& Poss. Comps.

Lower Elemental Limits: S

Upper Limits: C22 H263 N18

O16 S8 P8

Mass \& RIA Errors: 2 mDa $20 \%$

265.07535 Precursor Ion

C11 H13 N4 O2 S (7.5 9.5) -0.0

(1) 86.09623 Product Ion

C5 H12 N (0.5) -0.2

(2) 110.07160 Product Ion

C5 H8 N3 (3.5) 0.3

C7 H10 O (3.0) - 1.0

(3) 156.01083 Product Ion

C4 H4 N4 O S (5.0 6.0) 0.8

C6 H6 N O2 S (4.5 6.5) -0.5

(4) 108.04586 Product Ion

C H8 N4 S (0.0) -0.6

C3 H10 N O S (-0.5 0.5) - 1.9

C6 H6 N O (4.5) 1.5

(5) 109.05344 Product Ion

C H9 N4 S (-0.5) -0.8

C6 H7 N O (4.0) 1.2

(6) 135.01526 Product Ion

C7 H5 N S (6.0) 1.5

(7) 92.04986 Product Ion

C6 H6 N (4.5) 0.4

(8) 124.07560 Product Ion

C5 H8 N4 (4.0) 1.3

C7 H10 N O (3.5) -0.1

(9) 204.04553 Product Ion

C9 H8 N4 S (8.0) -0.9

(10) 111.04825 Product Ion

C3 H11 O2 S (-1.5 0.5) 0.8

(11) 218.07256 Product Ion

C11 H12 N3 S (7.5) -2.1

(12) 93.05705 Product Ion

C6 H7 N (4.0) -0.3

(12) 172.01830 Neutral Loss

C5 H6 N3 O2 S (4.5 6.5) 0.2

(11) 47.00279 Neutral Loss

H N O2 (1.0 2.0) 2.1

(10) 154.02710 Neutral Loss

C8 H2 N4 (10.0) - 0.8

(9) 61.02982 Neutral Loss

C2 H5 O2 (0.5) 0.9

(8) 140.99976 Neutral Loss

C4 H3 N3 O S (5.0 6.0) 0.1

C6 H5 O2 S (4.5 6.5) -1.3

(7) 173.02550 Neutral Loss

C5 H7 N3 O2 S (4.0 6.0) -0.4

(6) 130.06009 Neutral Loss

C4 H8 N3 O2 (2.5 3.5) -1.6

(5) 156.02191 Neutral Loss

C5 H6 N3 O S (4.5 5.5) -1.2

C10 H4 O2 (9.0) 0.8

(4) 157.02950 Neutral Loss

C5 H7 N3 O S (4.0 5.0) -1.5

C8 H3 N3 O (9.0) 1.9

C10 H5 O2 (8.5) 0.5

(3) 109.06451 Neutral Loss

C5 H7 N3 (4.0) 0.5

C7 H9 O (3.5) -0.8

(2) 155.00375 Neutral Loss

C4 H3 N4 O S (5.5 6.5) 1.0

C6 H5 N O2 S (5.0 7.0) - 0.3

(1) 178.97913 Neutral Loss

C6 S H N3 O2 (8.0 10.0) 0.2

\footnotetext{
${ }^{a}$ Each composition is followed by its rings and double bonds in parentheses or a range of rings and double bonds to account for elements that can have higher valences. ${ }^{6}$ The number after the parentheses is the difference in mDa between the measured exact mass and the exact mass calculated for the composition.
}

Exact Masses \& Poss. Comps. Lower Elemental Limits: S2 Upper Limits: C15 H180 N12 O11 S5 P5

Mass \& RIA Errors: 2 mDa $20 \%$ 182.00883 Precursor Ion C8 H8 N S2 (5.5) - 0.4

(1) 166.98495 Product Ion C7 H5 N S2 (6.0) -0.8

(2) 135.01526 Product Ion C7 H5 N S (6.0) 1.5

(3) 92.04986 Product Ion

C6 H6 N (4.5) 0.4

(4) 93.05705 Product Ion

C6 H7 N (4.0) -0.3

(4) 88.95179 Neutral Loss

C2 H S2 (2.5) -0.2

(3) 89.95898 Neutral Loss

C2 H2 S2 (2.0) -0.8

(2) 46.99358 Neutral Loss

C H3 S (0.5) -2.0

(1) 15.02389 Neutral Loss

C H3 (0.5) 0.4

Uniquely Correlated

Product Ions

319.10141 Precursor Ion

246.01453 Product Ion

239.07800 Product Ion

274.04535 Product Ion

233.00609 Product Ion

265.07535 Precursor Ion 110.07160 Product Ion 156.01083 Product Ion 124.07560 Product Ion 111.04825 Product Ion

182.00883 Precursor Ion 166.98495 Product Ion 
included ' $\mathrm{F}^{\prime}$, ' $\mathrm{P}$ ', 'SI', ' $\mathrm{I}$ ', and/or 'AS' in the input string to the IEP, the additional elements were considered and the maximum number of atoms of these elements was calculated in the same way. For example, including ' $\mathrm{PF}^{\prime}$ considered $\mathrm{P}$ and $\mathrm{F}$ as well as $\mathrm{C}, \mathrm{H}, \mathrm{N}, \mathrm{O}$, and $\mathrm{S}$. Including a ' $\mathrm{D}$ ' provided a screen display for each precursor ion and product ion:neutral loss comparison.

2. $\mathrm{Cl}$ and $\mathrm{Br}$ were also considered if the $\% 2 \mathrm{RIA}$ of the precursor ion was sufficiently large. If the $\% 2$ RIA exceeded $25 \%$ or $925 \%$, the maximum number of $\mathrm{Cl}$ atoms allowed was estimated as the integer of the $\% 2$ RIA (or $\% 2$ RIA -900) divided by $32 \%$ plus 1 . If the $\%$ RIA2 exceeded $80 \%$ or $980 \%$, the maximum number of $\mathrm{Br}$ atoms was the $\% 2$ RIA (or \%2 RIA - 900) divided by $97.3 \%$ plus 1 .

\section{Ion correlation calculations}

The four-step process for correlating precursor and single product ion:neutral loss pairs adapted from Grange et al. ${ }^{11}$ was:

1. All possible compositions having at least -0.5 rings and double bonds (RDB), that were consistent with the elemental limits considered, exact masses and mass error limit, and RIA and RIA tolerances, were calculated for the precursor and product ion and stored for further processing. The precursor ion compositions were calculated first to establish upper elemental limits for the subsequent calculation of the possible product ion compositions.

2. All possible neutral loss compositions were calculated based on the mass difference between the precursor ion and the product ion. The formulas characterized by an RDB value of no less than -2.0 were saved and stored for further processing.

3. Those precursor ion compositions were rejected which could not be derived by the summation of the number of atoms of each element in a product ion:neutral loss pair.

4. Product ion compositions that did not provide a remaining possible precursor ion when summed with a corresponding neutral loss composition were rejected, as were neutral loss compositions that did not provide a remaining possible precursor ion when summed with a corresponding product ion composition.

No attempt to map fragmentations from product ions to smaller product ions was programmed, ${ }^{11,12}$ because the fact that an exact mass difference between two product ions corresponds to a typical neutral loss does not mean that such a fragmentation actually occurred. For example, the $m / z 86$ base peak from chlorpromazine $(m / z 319)$ in Fig. 3(b) is a subunit of product ions (6), (8), and (11) in Table 4, but probably fragmented directly from the precursor ion shown in Fig. 3(b). Further complicating the issue is that one or more product ions could fragment from adduct species rather than from the precursor ion. ${ }^{12}$

\section{RIA error limits}

Both the adjusted RIAs (multiplied by 1.0466) and the RIAs calculated for each composition possible based on exact mass were used to estimate RIA error limits. The wider RIA error limits were used to reject or retain compositions based on the adjusted RIA. For an adjusted $\% 1$ RIA of $16.0 \%$, the calculated $\% 1$ RIA for $\mathrm{C}_{12} \mathrm{H}_{18} \mathrm{NO}^{+}$is $13.9 \%$, and the $20 \%$ or $15 \%$ error limits are $\pm 3.2 \%$ or $\pm 2.8 \%$, respectively. This composition would be retained based on agreement of $16.0 \pm 3.2 \%$ with $13.9 \%$. For RIAs greater than $1 \%$, RIA errors of $\pm 20 \%$ or $\pm 15 \%$ were used when the ion abundance of the monoisotopic ion exceeded 10000 or 100 000, respectively. Errors were often larger due to interferences when RIAs were less than $1 \%$. To compensate, the corresponding $\% 1$ RIA errors used were $\pm 0.4 \%$ and $\pm 0.3 \%$. \%2 RIAs less than $3 \%$ were not considered, and a $50 \%$ error limit was used for $\% 2$ RIAs up to $4 \%$. The current error limit was multiplied by 1.5 or 0.8 for $\% 2$ RIAs between $4 \%$ and $7 \%$ or greater than $30 \%$, respectively. Because severe RIA errors due to interferences were common below $m / z$ 100, RIAs were ignored below this mass limit. These empirical choices for the RIA errors were made based on the adjusted RIAs acquired for 15 individual standards. In no case were they exceeded for individual standards. These RIA error limits might be altered in light of data obtained in the future.

\section{Input and output program}

This program sends the exact masses (and RIAs, if the signal thresholds were met) for the precursor ion and a single product ion to the ICP. A sequence of cycles was followed.

\section{Initial upper elemental limits}

To satisfy the requirement that a product ion must be supplied along with the precursor ion to the ICP for it to function properly, the mass of an $\mathrm{H}$ atom was subtracted from the precursor ion to serve as a 'pseudo-product ion'. This tactic provided the possible compositions for the precursor ion without reference to the actual product ions. These possible compositions were used to establish upper elemental limits for later cycles. For example, considering $\mathrm{m} / \mathrm{z} 268.18933$ from Table 3 and the elements C, H, N, O, S, P and F, the initial upper elemental limits were determined by the ICP as the integer of the mass of the precursor ion divided by the atomic masses of each element to provide $\mathrm{C}_{22} \mathrm{H}_{267} \mathrm{~F}_{14} \mathrm{~N}_{19} \mathrm{O}_{16} \mathrm{P}_{8} \mathrm{~S}_{8}$. The four possible compositions initially found for the precursor ion in Table 3 narrowed the upper elemental limits to $\mathrm{C}_{15} \mathrm{H}_{28} \mathrm{~F}_{3} \mathrm{~N}_{7} \mathrm{O}_{3} \mathrm{~S}$.

\section{Error limits}

When wide error limits are chosen to ensure that no correct compositions are rejected, ${ }^{11}$ most of the measurement errors will actually be much smaller than these error limits. Doubling the exact mass error limit approximately doubles the number of possible compositions. Limiting the number of possible compositions for an ion by using a narrow error limit will eliminate compositions found for related ions for which a wider error limit is required to include the correct composition. Herein, multiple lists of compositions were generated for each set of precursor ion and product ion:neutral loss pairs based on two mass and two RIA error limits for the product ions. Using the smaller error limits, shorter lists of possible compositions were usually compiled for the ions and neutral losses. With the larger error limits, longer lists were usually generated containing additional product ions with low ion abundances for which the 
Table 5. Error limits applied to the precursor ion data until at least one composition is found

1. $2 \mathrm{mDa}$ and $20 \%$ for RA1 and RA2 (15\% when the RIA >900)

2. $2.01^{\mathrm{a}} \mathrm{mDa}$ and $30 \%$ for RA1 and RA2

3. $2.015 \mathrm{mDa}$ and $50 \%$ for RA1 and RA2

4. $44 \mathrm{mDa}$ and $20 \%$ for RA1 and RA2 ( $15 \%$ when the RIA >900)

5. $4.01 \mathrm{mDa}$ and $30 \%$ for RA1 and RA2

6. $4.015 \mathrm{mDa}$ and $50 \%$ for RA1 and RA2

7. $5 \mathrm{mDa}$ without consideration of RA1 or RA2.

Error Limits Applied to the Product Ion Data

1. $2 \mathrm{mDa}$ and $20 \%$ for RA1 and RA2 $(15 \%$ when the RIA >900)

2. $4 \mathrm{mDa}$ and $40 \%$ for RA1 and RA2

${ }^{\mathrm{a}}$ The fractional mass error limits serve as indicators for which error limits were used in the previous cycle.

measured errors fell between the smaller and larger error limits.

The mass error for the precursor ion need not be the same as for the product ions when two mass spectrometer stages are used. ${ }^{10}$ However, our mass errors were usually within $2 \mathrm{mDa}$ across the mass range observed using full scans, insource fragmentation, and a single-stage oa-TOFMS. Mass errors expressed as $\mathrm{mDa}$ avoided the high ppm errors associated with low-mass ions. At $\mathrm{m} / \mathrm{z} 77$ and 500, $2 \mathrm{mDa}$ corresponds to 26 and $4 \mathrm{ppm}$, respectively.

\section{Precursor ion error limits}

For the first cycle through the ICP, the mass and RIA error limits used were $\pm 2 \mathrm{mDa}$ and $\pm 20 \%$ (or $\pm 15 \%$ ). Because the measured mass and adjusted RIAs were $268.1893,16.7 \%$, and $2.0 \%$, while the calculated values were $268.1907,17.4 \%$, and $2.0 \%$, the correct composition passed the criteria. However, these error limits were determined empirically using methanol solutions of pure standards. For mixtures, wider error limits may be required due to interferences and lower abundances of ions from each analyte. These error limits will not find the correct composition and, generally, no compositions if one of the three measured values is badly distorted. Most often, an RIA is in error. The additional sets of error limits in Table 5 were used sequentially until at least one precursor ion composition was found. Using the first set of error limits, compositions were found for the precursor ion or highest-mass product ion from all 21 standards, for the precursor ions from a three-component mixture, and for six of seven precursor ions from a seven-component mixture. For 2-(methylthio)benzothiazole in the seven-component mixture $(m / z ~ 182)$, the third set of error limits found a single and correct composition for the precursor ion. A stepwise progression of slightly more lenient error limits avoided finding more numerous compositions than necessary, which would increase the upper elemental error limits and possibly result in multiple possible compositions remaining for the precursor ion after the product ion:neutral loss correlations were made.

\section{Product ion error limits}

The data for the precursor ion and each product ion were sent to the ICP sequentially. The error limits for the precursor ion

Published in 2008 by John Wiley \& Sons, Ltd. were those for which one or more compositions were found, and the error limits for the product ions were $2 \mathrm{mDa}$, and $20 \%$ (or 15\%) for the RIAs. The mass error limit for neutral loss masses determined as the mass difference between the precursor and product ions was 1.5 times the product ion mass error, and RIAs for neutral losses were not considered. During each cycle that found correlation, the upper elemental limits were recalculated and provided tighter elemental limits when one or more possible precursor ion compositions were no longer correlated with the product ion. For example, on consideration of the $m / z$ 116, 191 and 226 ions listed in Table 3, each eliminated one of the four original compositions and the upper elemental limits became $\mathrm{C}_{15} \mathrm{H}_{26} \mathrm{~F}_{3} \mathrm{~N}_{7} \mathrm{O}_{3}, \mathrm{C}_{15} \mathrm{H}_{26} \mathrm{~N}_{7} \mathrm{O}_{3}$ and $\mathrm{C}_{15} \mathrm{H}_{26} \mathrm{NO}_{3}$, successively.

\section{Re-correlation}

As noted earlier, if the upper elemental limits changed after the first precursor ion and product ion:neutral loss correlation, the precursor ion and each product ion were again tested for correlation using the most restrictive upper elemental limits found for the precursor ion. This practice eliminated the incorrect compositions for the $\mathrm{m} / \mathrm{z} 116$ and 191 ions in Table 3.

\section{Doubling the product ion error limits}

For product ions from the first 15 individual standards, the measured exact masses agreed to within $\pm 2 \mathrm{mDa}$ with the exact masses calculated for the correlated compositions of product ions that had ion abundances of $>10000,5000$ 10000 , and $1000-5000$ counts for 41 of 41,19 of 20 , and 50 of 66 comparisons, respectively. The ions with compositions providing calculated masses between $\pm 2-4 \mathrm{mDa}$ different from the measured values were correlated by cycling through the product ions again using a mass error of $\pm 4 \mathrm{mDa}$ and RIA errors of $\pm 40 \%$.

\section{Mass defect difference test}

Mass defect differences between the monoisotopic and +1 or +2 profiles can distinguish between product ion compositions containing atoms with very different mass defect differences. For two possible product ions, $\mathrm{C}_{7} \mathrm{H}_{9} \mathrm{O}^{+}(\mathrm{m} / \mathrm{z}$ 109.0648) and $\mathrm{C}_{4} \mathrm{H}_{13} \mathrm{OS}^{+}(\mathrm{m} / \mathrm{z}$ 109.0682) from the precursor ion, $\mathrm{C}_{10} \mathrm{H}_{16} \mathrm{NO}_{2} \mathrm{~S}^{+}$, the mass difference between the monoisotopic ions is only $3.4 \mathrm{mDa}$. Both compositions could correspond to a measured mass within $\pm 2 \mathrm{mDa}$. The calculated mass defect differences for the +2 isotopic peaks $(+2$ profile mass - monoisotopic mass -2 ) are +0.00571 and $0.00360 \mathrm{Da}$. If the measured mass defect difference fell within $\pm 3 \mathrm{mDa}$ of one of these values, the other composition could be eliminated. The mass defect difference tests were used when the isotopic profile abundances exceeded the product ion threshold to eliminate compositions that did not pass one or both mass defect difference tests, provided that at least one composition did so.

\section{List management}

For each cycle through the ICP that found correlation, the IOP appended the compositions found to a list of exact masses and corresponding compositions for the precursor ion and product ion:neutral loss pairs for the tighter product 
ion error limits of $\pm 2 \mathrm{mDa}$ and $20 \%$ (or $15 \%$ ). If a second set of cycles was required based on a change in the upper elemental limits found during the first set of cycles, fewer compositions for ions and neutral losses were sometimes found, and those not found were removed from the list.

A second list was compiled for the $4 \mathrm{mDa}$ and $\pm 40 \%$ product ion error limits. The second list often contained more product ions, because product ion:neutral loss pairs not contained in the first list satisfied the wider error limits. Additional compositions were common in the second list for product ion:neutral pairs already found with the tighter error limits. The two lists were merged by keeping the compositions from the first list and adding those found for exact masses not correlated with the precursor ion during the earlier cycles through the ICP. In at least one case, a product ion:neutral loss pair, which correlated only using the wider error limits, eliminated a precursor ion composition to provide tighter upper elemental limits. Re-correlation was performed for the wider error limits; fewer compositions were then found, and compositions were removed from the list. Finally, the mass defect difference tests were applied to the merged list and failed compositions were removed from the final list.

The output file for a three-component mixture containing the text files prepared by the IEP in the lower portion of Table 1 and the final list in Table 4 were saved as a text file. The elements $\mathrm{C}, \mathrm{H}, \mathrm{Br}, \mathrm{Cl}, \mathrm{N}, \mathrm{O}, \mathrm{P}$ and $\mathrm{S}$ were considered as indicated by the 'elemental limits' in Table 4.

Table 2 lists the 22 monoisotopic ions for the threecomponent mixture that met the thresholds for precursor or product ions described above. Three of the ions were precursor ions and 19 were product ions. Table 4 lists the nine product ions that were correlated with only one of the precursor ions. Five ions with $\mathrm{m} / \mathrm{z}$ less than 110 were correlated with two or all three precursor ions, while two ions did not correlate with any of the precursor ions. Lowmass ions are often compositional subunits of multiple precursor ions. The $m / z 92$ ion corresponded to $\mathrm{C}_{6} \mathrm{H}_{6} \mathrm{~N}^{+}$and could be a fragment from $\mathrm{C}_{17} \mathrm{H}_{20} \mathrm{ClN}_{2} \mathrm{~S}^{+}, \mathrm{C}_{11} \mathrm{H}_{13} \mathrm{~N}_{4} \mathrm{O}_{2} \mathrm{~S}^{+}$, or $\mathrm{C}_{8} \mathrm{H}_{8} \mathrm{~N}_{2} \mathrm{~S}^{+}$. Its origin is not determinable from the threecomponent mass spectrum. The mass error limit for all three precursor ions was $2 \mathrm{mDa}$ and the RIA error limits were $15 \%$ for the $m / z 319$ and 182 ions and 20\% for the $m / z 265$ ion. The 'lower elemental limits' provided in Table 4 were automatically set to one $\mathrm{Cl}$ atom for the $\mathrm{m} / z 319$ ion, one $\mathrm{S}$ atom for the $m / z 265$, and two $S$ atoms for the $m / z 182$ ion, based on their $\% 2$ RIAs.

For composite mass spectra containing numerous ions, spectra containing high-mass precursor ions, or when RIAs were not calculated, only the most common elements should be considered before including elements such as $\mathrm{P}, \mathrm{F}, \mathrm{Si}$, I or As. When $\mathrm{F}$ was considered for the three-component mixture, $\mathrm{C}_{17} \mathrm{H}_{17} \mathrm{ClFN}_{2} \mathrm{O}^{+}$and $\mathrm{C}_{8} \mathrm{H}_{14} \mathrm{FN}_{4} \mathrm{O}_{3} \mathrm{~S}^{+}$were the compositions found for the $\mathrm{m} / \mathrm{z} 319$ and 265 precursor ions, respectively.

For a mixture of seven standards, 2-aminopyridine, 2-amino4,6-dimethylpyrimidine, 2-(methylthio)benzothiazole, DEET, $\mathrm{N}$-butylbenzenesulfonamide, carbamazepine and chlorpromazine, the correct compositions, $\mathrm{C}_{7} \mathrm{H}_{5} \mathrm{~N}_{2}^{+}, \mathrm{C}_{6} \mathrm{H}_{10} \mathrm{~N}_{3}^{+}, \mathrm{C}_{8} \mathrm{H}_{8} \mathrm{NS}_{2}^{+}$,
$\mathrm{C}_{12} \mathrm{H}_{18} \mathrm{NO}^{+}, \mathrm{C}_{10} \mathrm{H}_{16} \mathrm{NO}_{2} \mathrm{~S}^{+}, \mathrm{C}_{15} \mathrm{H}_{13} \mathrm{~N}_{2} \mathrm{O}^{+}, \mathrm{C}_{17} \mathrm{H}_{20} \mathrm{ClN}_{2} \mathrm{~S}^{+}$, respectively, were found when only $\mathrm{C}, \mathrm{H}, \mathrm{N}, \mathrm{O}, \mathrm{S}, \mathrm{Cl}$ and $\mathrm{Br}$ were considered for the exact masses from the mass spectra in Fig. 5. The ion abundances were less for the more numerous ions and larger errors for the precursor ions resulted. Seven ions were determined to be precursor ions and 11 product ions passed the ion abundance threshold. Only two product ions were uniquely correlated and the other nine product ions were multiply correlated.

When $\mathrm{P}$ was added, all seven of the compositions remained correct, but adding $\mathrm{F}$ in place of $\mathrm{P}$ or in addition to $\mathrm{P}$ provided five correct compositions, $\mathrm{C}_{17} \mathrm{H}_{17} \mathrm{ClFN}_{2} \mathrm{O}^{+}$for chlorpromazine, and $\mathrm{C}_{5} \mathrm{H}_{9} \mathrm{FNOS}_{2}^{+}$for 2-(methylthio)benzothiazole. Additional compositions were also found: $\mathrm{C}_{9} \mathrm{H}_{19} \mathrm{FNO}_{2}^{+}$for DEET and $\mathrm{C}_{2} \mathrm{H}_{8} \mathrm{FN}_{2} \mathrm{O}^{+}$for 2-aminopyridine. For chlorpromazine, considering $\mathrm{F}$ provided correlation for $\mathrm{C}_{6} \mathrm{H}_{8} \mathrm{NO}^{+}$with $\mathrm{C}_{17} \mathrm{H}_{17} \mathrm{ClFN}_{2} \mathrm{O}^{+}$that contained $\mathrm{F}$ and $\mathrm{O}$, but not with the correct precursor ion composition, $\mathrm{C}_{17} \mathrm{H}_{20} \mathrm{ClN}_{2} \mathrm{~S}^{+}$, that lacked $\mathrm{O}$ atoms. The correct composition was then eliminated as possible when the upper elemental limits were tightened in light of the erroneous correlation.

For 2-(methylthio)benzothiazole, the monoisotopic ion abundance was only 12220 counts and the areas of the +1 and +2 isotopic peaks were less than 1000 . The adjusted $\% 1$ RIA was only $7.29 \%$, which was $33 \%$ lower than the $\% 1$ RIA for the correct composition, but only $4 \%$ lower for the incorrect composition. Hence, the incorrect composition was found before the error limits were increased to the third set in Table 5, and the correct precursor ion composition was never found.

For the seven correct compositions, hundreds to thousands of references were found in the extensive SciFinder ${ }^{\mathbb{R}}$ database $^{8,16}$ for the standards in the mixture and many fewer for other isomers. Few references were found for any isomers of the compositions that contain an $\mathrm{F}$ atom: $\mathrm{C}_{17} \mathrm{H}_{16} \mathrm{ClFN}_{2} \mathrm{O}$ (21), $\mathrm{C}_{8} \mathrm{H}_{13} \mathrm{FN}_{4} \mathrm{O}_{3} \mathrm{~S}$ (0), $\mathrm{C}_{5} \mathrm{H}_{8} \mathrm{FNOS}_{2}$ (0), $\mathrm{C}_{9} \mathrm{H}_{19} \mathrm{FNO}_{2}$ (4), and $\mathrm{C}_{2} \mathrm{H}_{7} \mathrm{FN}_{2} \mathrm{O}(0)$.

For flecainide, considering only the elements $\mathrm{C}, \mathrm{H}, \mathrm{N}, \mathrm{O}, \mathrm{S}$, $\mathrm{Cl}$, and $\mathrm{Br}$ yielded one possible precursor ion composition, $\mathrm{C}_{16} \mathrm{H}_{23} \mathrm{~N}_{4} \mathrm{O}_{9}^{+}$. When $\mathrm{F}$ was also considered, two possible compositions were found, $\mathrm{C}_{15} \mathrm{H}_{18} \mathrm{~F}_{3} \mathrm{~N}_{8} \mathrm{O}_{3}^{+}$ and $\mathrm{C}_{17} \mathrm{H}_{21} \mathrm{~F}_{6} \mathrm{~N}_{2} \mathrm{O}_{3}^{+}$. The non-F-containing composition was not found, because the mass error for the prominent $\mathrm{m} / \mathrm{z} 301$ product ion was $-2.5 \mathrm{mDa}$ for the single composition found, $\mathrm{C}_{10} \mathrm{H}_{9} \mathrm{~N}_{2} \mathrm{O}_{9}^{+}$, while with $\mathrm{F}$ considered, the mass errors found for two compositions, $\mathrm{C}_{9} \mathrm{H}_{4} \mathrm{~F}_{3} \mathrm{~N}_{6} \mathrm{O}_{3}^{+}$and $\mathrm{C}_{11} \mathrm{H}_{7} \mathrm{~F}_{6} \mathrm{O}_{3}^{+}$, were -1.3 and $-1.6 \mathrm{mDa}$, respectively. With compositions found for the tighter product ion error limits, the composition found with the looser error limits was not saved in the final list of exact masses and compositions. The number of references found by SciFinder for the molecular compositions $\mathrm{C}_{16} \mathrm{H}_{22} \mathrm{~N}_{4} \mathrm{O}_{9}, \mathrm{C}_{15} \mathrm{H}_{17} \mathrm{~F}_{3} \mathrm{~N}_{8} \mathrm{O}_{3}$ and $\mathrm{C}_{17} \mathrm{H}_{20} \mathrm{~F}_{6} \mathrm{~N}_{2} \mathrm{O}_{3}$ were 2, 0, and 641 for flecainide, respectively. Had the identity of this compound been unknown, flecainide would be purchased to confirm this tentative identification by mass spectral comparisons at the three orifice 1 voltages. This example illustrated that $\mathrm{F}$ is present in some compounds and that ignoring it could lead to an incorrect tentative identification. The limited number of references for the non-F-containing composition would encourage consideration of additional elements. 

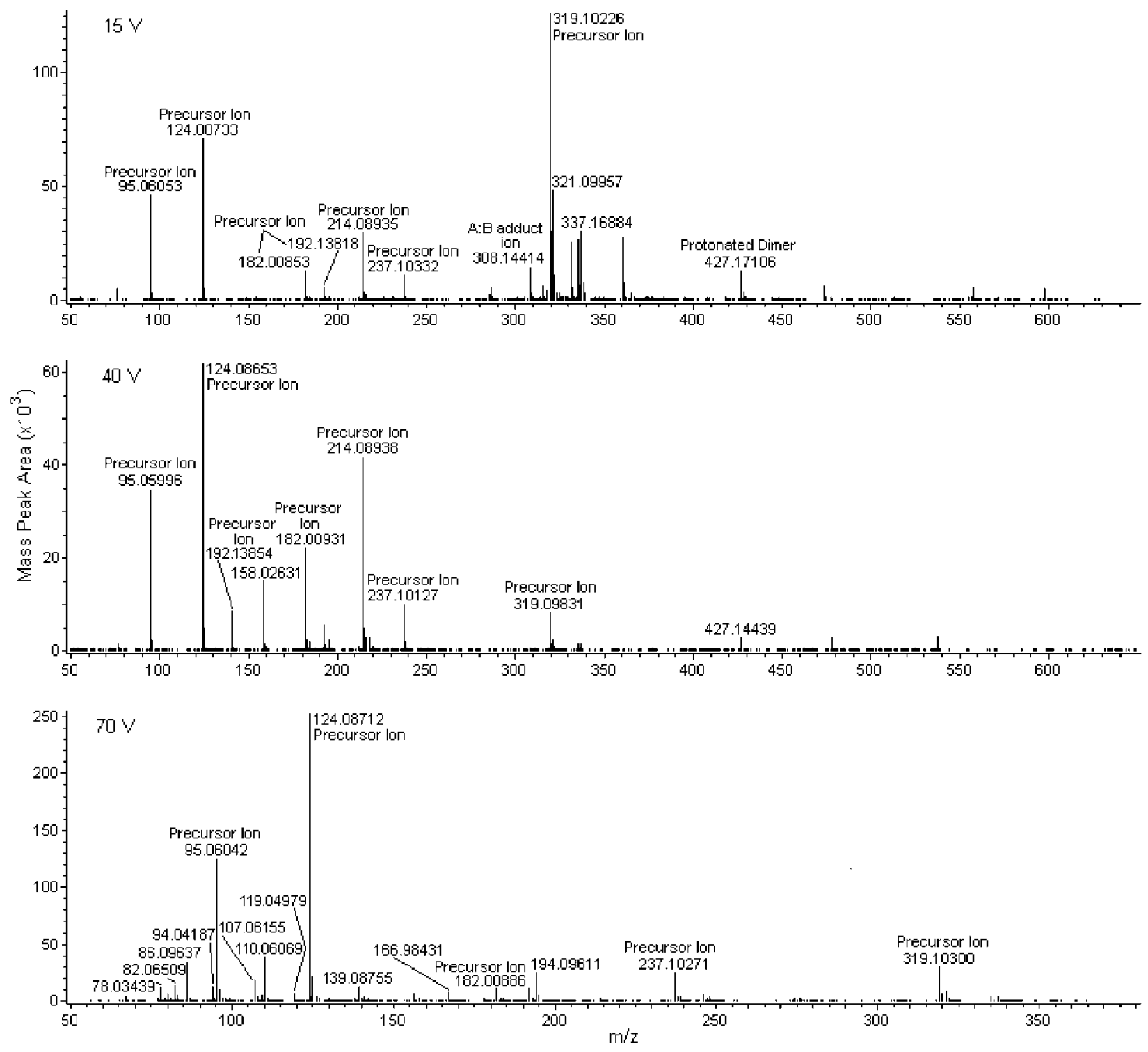

Figure 5. Mass spectra acquired with minimal, moderate, and major fragmentation for a seven-component mixture of 2-aminopyridine, 2-amino-4,6-dimethylpyrimidine, 2-(methylthio)benzothiazole, DEET, $\mathrm{N}$-butylbenzulfonamide, carbamazepine, and chlorpromazine.

\section{RIA calibrants}

After data was acquired for the original 15 standards and two mixtures, the instrument was shut down and moved so that an air conditioner could be replaced. Afterward, the temperature in the laboratory was about $10^{\circ} \mathrm{F}$ cooler, and the correction factor (1.0466) for the RIAs was no longer reasonable. After adding flecainide to the three calibrant solutions to provide an $\mathrm{m} / \mathrm{z} 415$ ion, a correction factor of 0.9625 was calculated based on the average RIA errors obtained for 25 ions from the three mass calibrant solutions using the appropriate orifice 1 voltage for each. For future work, a simple program could be written to use the three mass calibrant solutions as RIA calibrant solutions. The program could then be run daily to establish the correction factor.

\section{Imperfections and pitfalls}

Numerous assumptions were codified within the software. Many were adjusted to ensure that the correct compositions

Published in 2008 by John Wiley \& Sons, Ltd. were found for the analytes and are subject to additional modification as the ICP is used to identify compounds. Additional exact mass difference tests might be added in light of ongoing experience. For example, the base peak from cephalexin at $m / z 304$ resulted from the loss of $\mathrm{CO}_{2}$ from its carboxylic acid group, and the protonated molecule was not evident in the mass spectrum. A test for the loss of $\mathrm{CO}_{2}$ could be added as was done for the loss of $\mathrm{H}_{2} \mathrm{O}$ from $2,2^{\prime}-$ thiodiethanol. Instances will arise where incorrect precursor ion compositions are found based on unusual circumstances such as the very facile fragmentation of compounds to provide product ions at orifice 1 voltages of 15 and $40 \mathrm{~V}$. Highly thermolabile compounds might thermally degrade in the $300^{\circ} \mathrm{C} \mathrm{He}$ gas, and the mass spectrum obtained would result from one or more degradation products. A high-mass precursor ion having an abundance of less than 10000 counts so that no RIAs are calculated can overload the ICP program when $\mathrm{F}$ and $\mathrm{P}$ are considered. Often, the correct composition for high-mass precursor ions with low abundances for which 
RIAs are not calculated is not found. Ion-molecule reactions for mixtures of compounds can yield ions not evident for the individual compounds, which could correlate with an incorrect precursor ion composition. No chemical insights are applied to ion compositions that are arithmetically possible and some may be highly improbable. The halogen test considered up to four $\mathrm{Cl}$ or $\mathrm{Br}$ atoms in an ion. More than four such atoms might yield meaningless results. However, the appearance of the mass spectra for ions containing more than four halogen atoms would immediately reveal their presence. Finally, only the elements most commonly found in organic contaminants were included, which neglects numerous elements in the periodic table. However, if the correct composition for the precursor ion is found for at least $80 \%$ of the mass spectra examined, the ion correlation tool described herein will be valuable for identifying analytes by both experts and novice mass spectrometrists.

\section{CONCLUSIONS}

Measured exact masses provided high specificity for determining if and how ions were interrelated. Exact mass difference filters were used to determine which ions were due to +1 or +2 isotopes, loss of $\mathrm{H}$, ammonium adducts, oxygenated analytes, protonated or ammoniated dimers, loss of water, or the presence of between 1 and $4{ }^{37} \mathrm{Cl}$ or

${ }^{81} \mathrm{Br}$ atoms. Using three orifice 1 voltages provided minimal, modest, and major in-source CID to differentiate among precursor, dimer-related, and product ions. Automatically processing $\mathrm{m} / \mathrm{z}$ vs. ion abundance lists from mass spectra acquired under the three CID conditions and applying exact mass difference and RIA filters provided substantial mass spectral interpretation for 21 individual analytes and mixtures of three and seven compounds.

The ability to identify multiple compounds that provide composite mass spectra based on measured exact masses and RIAs rather than on slight retention time and chromatographic peak shape differences should be extremely useful when using surface sampling, in-air ionization. Hundreds of cotton swab, wipe samples could be collected and rapidly mass analyzed to thoroughly characterize Superfund sites where multi-component chemical wastes have been dumped in localized areas.

At least three groups have now developed software to correlate precursor ions with their product ion:neutral loss pairs and have successfully demonstrated the power of their programs for reaching tentative identifications of low-mass compounds (up to $415 \mathrm{Da}$ in this paper). The software suite (ion extraction program, ion correlation program, and input and output program) is available from the author at no cost. Adaptation to other oa-TOFMS systems would require only modification of the ion extraction program to read in the $m / z$ values and ion abundances from text files provided by the data system and adjustment of thresholds and error limits.

\section{Notice}

The United States Environmental Protection Agency (US EPA), through its Office of Research and Development (ORD), funded and performed the research described. This manuscript has been subjected to the US EPA's peer and administrative review and has been approved for publication.

\section{REFERENCES}

1. Grange AH. Environ. Forensics 2008; 9: 127.

2. Grange AH. Environ. Forensics 2008; 9: 137.

3. Ojanperä S, Pelander A, Pelzing M, Krebs L, Vuori E, Ojanperä L. Rapid Commun. Mass Spectrom. 2006; 20: 1161.

4. Grange AH, Donnelly JR, Brumley WC, Sovocool GW. Anal. Chem. 1995; 68: 553.

5. Grange AH, Brumley WC. J. Am. Soc. Mass Spectrom. 1997; 8: 170.

6. Grange AH, Sovocool GW. Environ. Forensics 2007; 8: 391.

7. Ibáñez M, Sancho JV, Pozo AJ, Niessen W, Hernandez F. Rapid Commun. Mass Spectrom. 2005; 19: 169.

8. Grange AH, Winnik W, Ferguson P, Sovocool GW. Rapid Commun. Mass Spectrom. 2005; 19: 2699.

9. Garcia-Reyes JF, Ferrer I, Thurman EM, Molina-Diaz AM, Fernandez-Alba AR. Rapid Commun. Mass Spectrom. 2005; 19: 2780.

10. Suzuki S, Ishii T, Yasuhara A, Sakai S. Rapid Commun. Mass Spectrom. 2005; 19: 3500.

11. Grange AH, Zumwalt MC, Sovocool GW. Rapid Commun. Mass Spectrom. 2006; 20: 89.

12. Kaufmann A. Rapid Commun. Mass Spectrom. 2007; 21: 2003.

13. Cody RB, Laramee JA, Durst HD. Anal. Chem. 2005; 77: 2297.

14. Available: http://physics.nist.gov/PhysRefData/Compositions/.

15. Španiĕl P, Davies S, Smith D. Rapid Commun. Mass Spectrom. 1998; 12: 763.

16. Available: http://www.cas.org/SCIFINDER/scicover2.html. Chemical Abstract Services, American Chemical Society: Columbus, OH, USA. 